\title{
Inductive Thermal Effect of Ferrite Magnetic Nanoparticles
}

\author{
Jeotikanta Mohapatra, Meiying Xing and J. Ping Liu * \\ Department of Physics, University of Texas at Arlington, Arlington, TX 76019, USA; \\ jeotikanta.mohapatra@uta.edu (J.M.); meiying.xing@mavs.uta.edu (M.X.) \\ * Correspondence: pliu@uta.edu; Tel.: +1-817-272-2815
}

Received: 21 August 2019; Accepted: 24 September 2019; Published: 30 September 2019

\begin{abstract}
Localized heat induction using magnetic nanoparticles under an alternating magnetic field is an emerging technology applied in areas including, cancer treatment, thermally activated drug release and remote activation of cell functions. To enhance the induction heating efficiency of magnetic nanoparticles, the intrinsic and extrinsic magnetic parameters influencing the heating efficiency of magnetic nanoparticles should be effectively engineered. This review covers the recent progress in the optimization of magnetic properties of spinel ferrite nanoparticles for efficient heat induction. The key materials factors for efficient magnetic heating including size, shape, composition, inter/intra particle interactions are systematically discussed, from the growth mechanism, process control to chemical and magnetic properties manipulation.
\end{abstract}

Keywords: iron oxide; magnetic nanoparticles; magnetic nanorods; nanocrystals nanoassemblies; superparamagnetism; colloidal stability; hyperthermia

\section{Introduction}

Ferrite $\left(\mathrm{MFe}_{2} \mathrm{O}_{4}, \mathrm{M}=\mathrm{Mn}, \mathrm{Fe}, \mathrm{Co}, \mathrm{Ni}\right.$ and $\mathrm{Zn}$ ) magnetic nanoparticles (typically, of size 5-100 nm) have attracted profuse attention because they are at the interfaces of chemistry, physics and biology, due to their remarkable size and shape-dependent magnetic properties [1-3]. Scientists have developed methods to produce magnetic nanoparticles with fine control of the morphology [4-6]. Many new phenomena such as superparamagnetism, superferromagnetism, and superspin glass have been observed in these magnetic nanoparticles (MNPs) [7-9]. Moreover, in the nano-regime the magnetic properties such as coercivity $\left(H_{C}\right)$, saturation magnetization $\left(M_{S}\right)$ and susceptibility $(\chi)$ strongly vary with the size, shape, and composition of the magnetic nanoparticles $[2,6,10]$. These unique magnetic properties, small size and biocompatibility make them particularly promising in various biomedical applications, for instance contrast enhancement in magnetic resonance imaging (MRI), nano-sized carrier in drug delivery, mediators in converting electromagnetic energy to heat, and as magnetic-targeting and bio-sensing agents [11-15]. All these biomedical applications require the MNPs to have high magnetic moments with small sizes and a narrow particle-size distribution, so that the nanoparticles could have well-defined physical and chemical properties [11,16-18]. A general picture in Figure 1 schematically illustrates the uses of MNPs in four important areas of cancer theranostics.

In general, when the magnetic nanoparticle suspension is subjected to an alternating current magnetic field (ACMF), it can demonstrate prominent heating effects related to energy losses during the magnetization reversal of the nanostructures. This heating ability depends on the properties of the nanostructures, such as mean size, magnetization and magnetic anisotropy, and the ACMF amplitude $\left(H_{a c}\right)$ and frequency $(f)[19,20]$. Therefore, to improve the inductive heating characteristics of magnetic nanostructures, many approaches have been taken to improve the magnetic properties of the nanostructures [21-25]. Over the past few years, substantial progress has been made to precisely control the size, composition, morphology and multifunctionalities of magnetic nanostructures [11,26-29]. 
Such studies have improved our understanding of their unique nanoscale magnetic properties and demonstrated the great potential of these MNPs in hyperthermia applications. For example, MNPs with hard and soft ferrite core-shell architecture exhibit strong exchange-coupling, which enhances the magnetic heating power [30,31]. The magnetic nanostructure comprises of several domains such as nanoflowers, nanoclusters and nanoassemblies have also been shown to enhance the heating power $[24,25]$. In this review, we begin by briefly introducing the fundamental principles of MNPs. We then focus on the chemical synthesis, in particular the organic phase synthesis, of a series of MNPs with controlled size, composition, and morphology. Finally, we establish a relationship across the magnetic and inductive heating properties of MNPs.

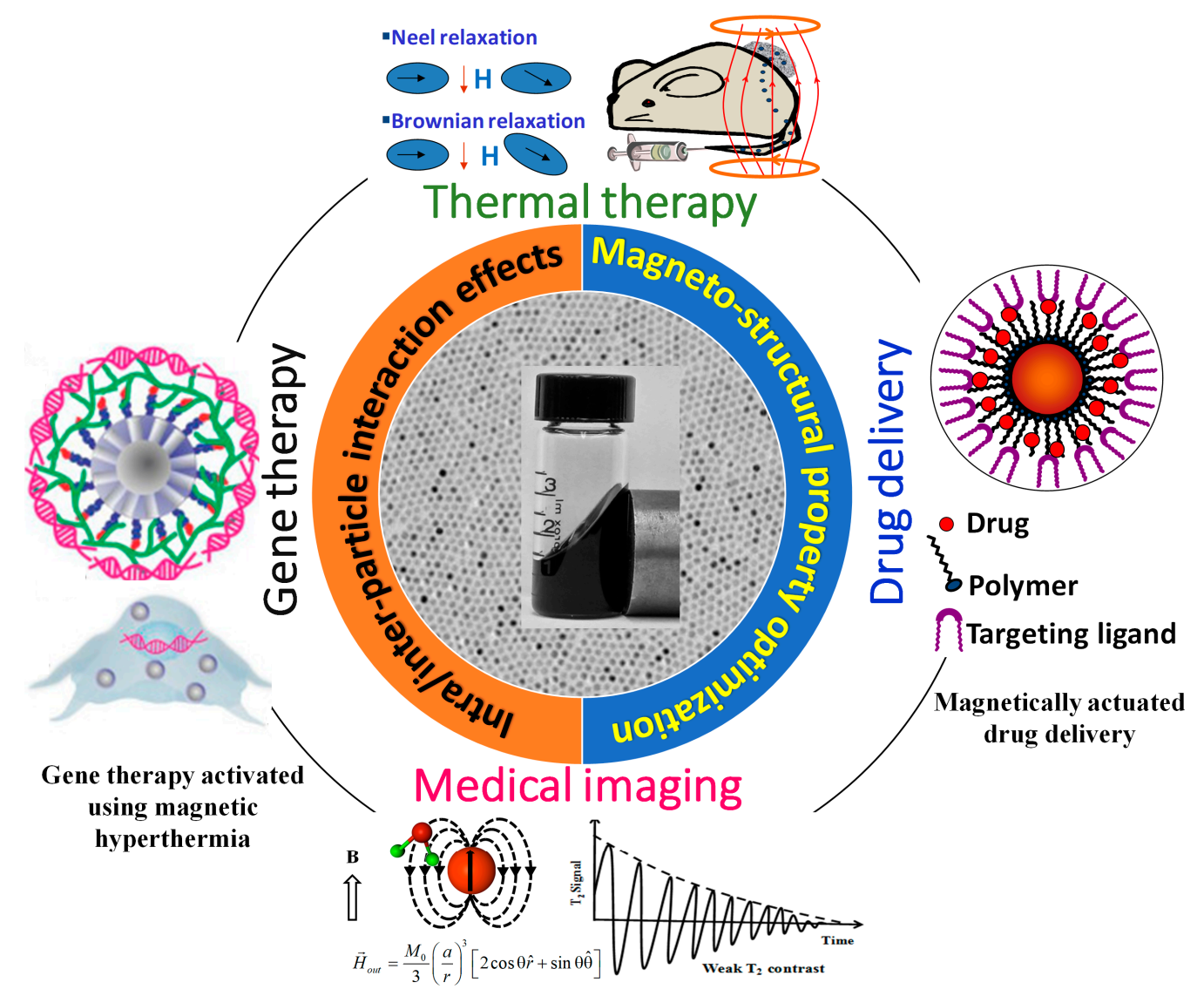

Figure 1. Based on the heat activation ability, these nanostructures have been utilized in cancer therapy, on-demand drug carrier and gene therapy applications [32,33]. The magnetic nanoparticles have also been as contrast agent in magnetic particle imaging (MPI) and magnetic resonance imaging (MRI).

\section{Characteristics of Magnetic Nanoparticles and Inductive Heating Principles}

\subsection{Magnetism at Nanoscale}

As first predicted by Frenkel and Dorfman, when the size of the ferromagnet or ferrimagnet decreases below a critical size, the amount of energy required to produce domain walls becomes greater than the reduction in the magnetostatic energy [34]. As a consequence, only single domain formation is favored. A single domain particle consists of large numbers of atomic spins and, thus, can be viewed as 'supermoment' that has a magnetic moment $\sim 10^{3}$ to $10^{5} \mu_{B}$ [35]. The single domain size can be estimated from the equation [34-36]:

$$
D_{S D}=\frac{18(A K)^{\frac{1}{2}}}{\mu_{0} M_{S}^{2}}
$$


where $\mu_{0}$ is the permeability of free space $\left(4 \pi \times 10^{-7} \mathrm{H} / \mathrm{m}\right), A$ is the exchange stiffness in $\mathrm{J} / \mathrm{m}$ and $\mathrm{K}$ is the magnetocrystalline anisotropy in $\mathrm{J} / \mathrm{m}^{3}$. For example, the typical value of single domain size is around $128 \mathrm{~nm}$ for $\mathrm{Fe}_{3} \mathrm{O}_{4}$, while for $\mathrm{MnFe}_{2} \mathrm{O}_{4}$ it is $50 \mathrm{~nm}$ (due to a smaller $K$ and a higher $M_{S}$ ) [37-39]. Further, at the particle size $d=D_{S D}$, the single domain prefers to be uniformly magnetized along one of its anisotropic easy axes, which leads to a strong enhancement in coercivity. Below $D_{S D}$, due to the decrease of the magnetic anisotropy energy $\left(E_{a}=K V, V\right.$ is volume of the particle) the coercivity value decreases with decrease in the size (see Figure 2) [40]. On further reduction in size, the anisotropy energy value decreases further and becomes comparable to or even lower than the thermal energy $\left(k_{B} T, k_{B}\right.$ is Boltzmann constant). As a consequence, the energy barrier for magnetization reversal is dominated by thermal energy (Figure 3A, orange line). Thus, the supermoment thermally fluctuate like spins in a paramagnetic material, which leads to a net magnetization of zero; this phenomenon is called superparamagnetism. Superparamagnetic materials have no coercivity at room temperature, whereas ferromagnetic materials have a high coercivity. On application of an external magnetic field, the superparamagnetic nanoparticles react like the paramagnets (i.e., supermoment rotation) with the one exception that their magnetic susceptibility ' $\chi$ ' is much larger or even comparable to bulk value. However, in ultra-small sized MNPs, the $\chi$ value is always lower than the bulk value. This lower value is explained by the magnetically inactive surface atomic layer of the nanoparticles. Since a large fraction of atoms reside at the surface of MNPs, the surface spin disorder effect is dramatically pronounced with decrease of MNPs size. Thus, with a decrease of the size of MNPs, $\chi$ value decreases. The alternative approach to modulate the magnetic properties $\left(\chi\right.$ and $\left.H_{C}\right)$ at the nanoscale is to develop the anisotropy through other mechanisms such as the shape anisotropy and the exchange coupling. The effects of shape anisotropy and the exchange coupling on the magnetic properties of MNPs will be disscused in the Sections 3.3 and 3.4, respectively.

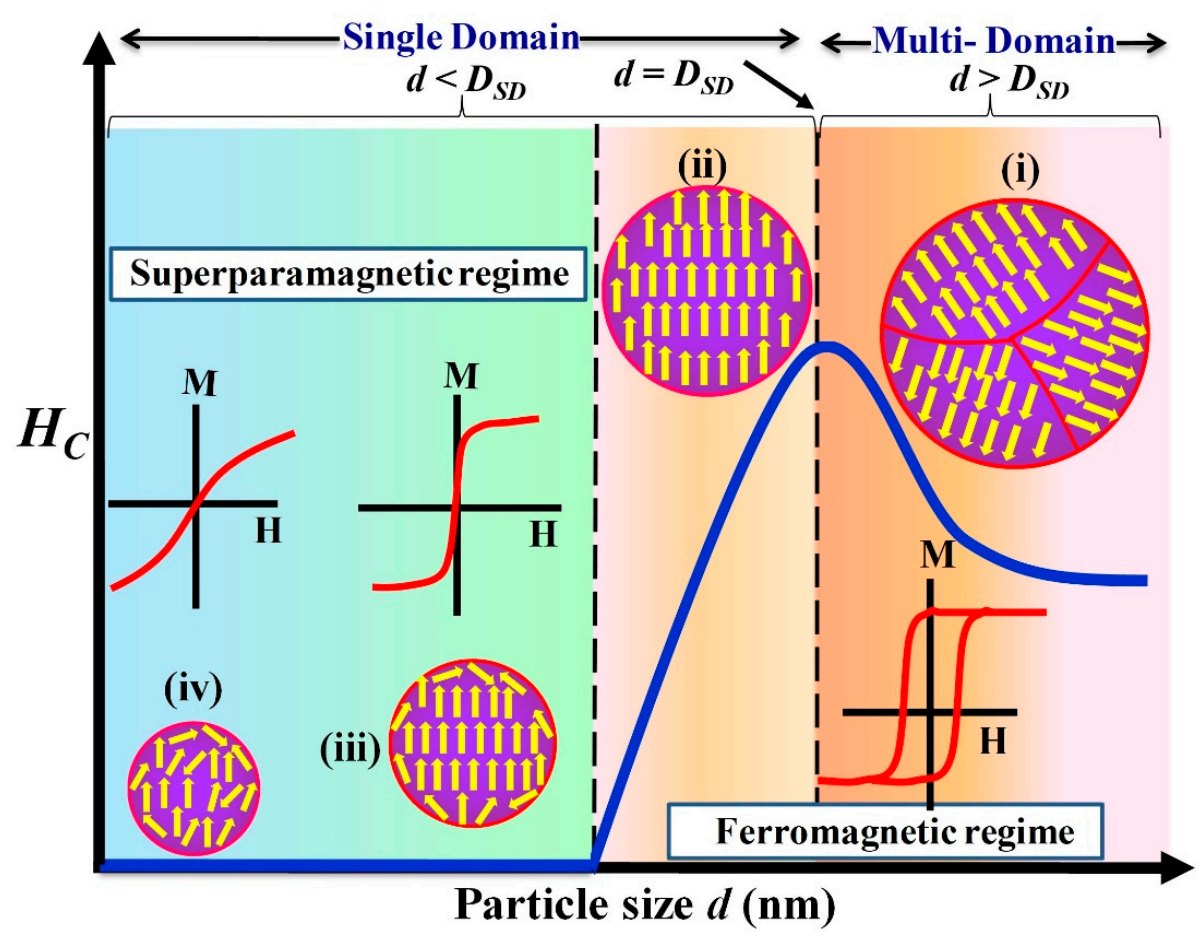

Figure 2. Variation of coercivity $\left(H_{C}\right)$, spin ordering and the nature of the magnetization curve with MNPs size ' $d$ '. (i) With a decrease of the size of ferromagnetic particles, the $H_{C}$ initially increases and then attains a maximum value at the critical single domain size $\left(D_{S D}\right)$ due to coherent rotation. (ii) Further, in the single domain regime $\left(d<D_{S D}\right)$, the $H_{C}$ decreases as the particle size decreases and (iii) becomes zero at the superparamagnetic regime due to the thermal agitation. (iv) Finally, in ultra-small regimes $(d \leq 3 \mathrm{~nm})$, due to high-spin disorder of elemental spins, the MNPs exhibit a linear relationship between the magnetization and the applied magnetic field [35]. 
(A)

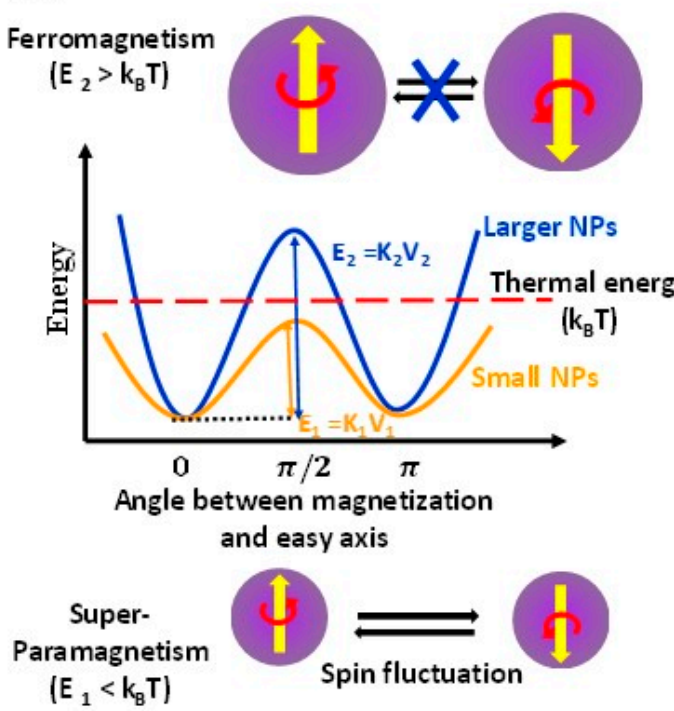

(B)

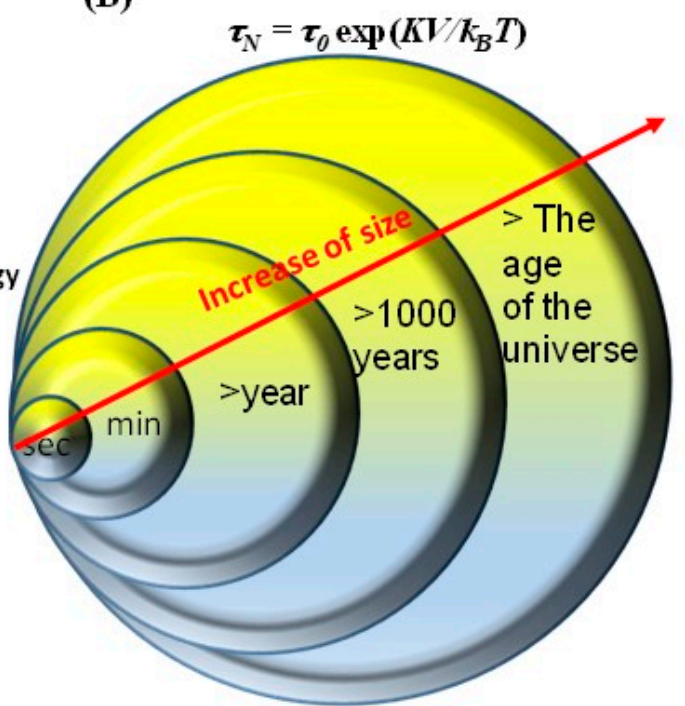

Figure 3. (A) The top of (A) depicts the reversal of magnetization in ferromagnetic particles. The energy diagram below illustrates the difference in energy barrier for a large particle behaving as ferromagnet and a small particle behaving as superparamagnet. The bottom of (A) depicts the relaxation process in superparamagnetic particles. (B) A typical correlation between the Néel relaxation time and the MNPs diameters. MNPs with extremely high $\tau_{N}$ are promising for recording media applications.

The superparamagnetic relaxation time can be modeled by the Néel-Brown theory as shown below [41,42]:

$$
\tau_{N}=\tau_{0} \exp \left[\frac{E_{a}}{k_{B} T}\right]
$$

where $E_{a}=K V$ is the anisotropy energy which determines the flipping angle of the nanoparticle, and $\tau_{0}$ is an attempt relaxation time factor that lies in the range of $10^{-9}$ to $10^{-13} \mathrm{~s}$ [43]. The relaxation time exponentially increases with the increase of MNPs size (Figure 3B). When the relaxation time ' $\tau_{N}$ ' is small or comparable to the time scale of the experimental technique $\left(\tau_{N} \leq t_{m}, t_{m}\right.$ is the measuring time), we measure an average value of the magnetization; however, if the $\tau_{N} \geq t_{m}$, we measure the instantaneous value of the magnetization. The transition temperature at which $\tau_{N}=t_{m}$ is known as superparamagnetic blocking temperature $\left(T_{B}\right)$ and can be expressed as

$$
T_{B}=\frac{K V}{k_{B} \ln \left(t_{m} / \tau_{0}\right)}
$$

From the above equation it is clear that the magnetocrystalline anisotropy and the volume of magnetic nanoparticles are the two key parameters on which the $T_{B}$ depends. The larger the size of the nanoparticles, the larger ' $k_{B} T$ ' is required for superparamagnetic transition. Thus, $T_{B}$ increases with the increase in the size of the nanoparticles. However, in the case of nanoparticle assemblies and multicore nanoparticles, the interparticle interaction modifies the energy barrier and produces collective properties. The magnetic properties of interacting MNPs are well described by the Vogel-Fulcher model $[44,45]$

$$
\tau=\tau_{0} \exp \left[\frac{E_{a}}{k_{B}\left(T-T_{0}\right)}\right]
$$

where $T_{0}$ is known as Vogel-Fulcher temperature, a measure of the interaction strength and $E_{\mathrm{a}} / k_{\mathrm{B}}$ is the activation energy required to overcome the barrier of the reversal of the magnetization. With a further increase of nanoparticle interaction, a spin-glass like collective state can be formed (known as superspin glass) $[35,46]$. When the strength of the interparticle interactions is strong enough, a long-range ferromagnetic ordering can occur, and the state is known as superferromagnet [41,42]. 
Recently, the superspin glass and superferromagnetic ordering have been observed in $\mathrm{Fe}_{3} \mathrm{O}_{4}$ and $\mathrm{Co}$ nanoparticle systems $[47,48]$. As discussed above the magnetic properties of MNPs can be controlled with exploitation of several parameters such as size, composition and morphology. In addition, the inter/intra particles interactions can be controlled to further optimize the magnetic properties, which will be discussed in the Section 3.4.

\subsection{Basic Principles of Inductive Heating}

\subsubsection{Effects of Magnetic Anisotropy and Magnetic Susceptibility}

When colloids of magnetic nanoparticles are subjected to an ac magnetic field, they convert electromagnetic energy into heat due to losses from the reversal of magnetization [49-51]. The magnetization reversal mainly occurs through two different processes: Hysteresis loss (seen in ferromagnetic NPs) and susceptibility loss (seen in superparamagnetic NPs). Hysteresis loss strongly depends on the field amplitude $\left(H_{a c}\right)$ as well as the magnetic coercive field $\left(H_{K}=2 K / \mu_{0} M_{S}\right.$, however in experiment the coercivity will be much lower than the $H_{K}$ ) [52]. When the ACMF is applied to a ferromagnetic particle with moment $(\mu)$, the magnetization state becomes metastable, as shown in Figure $4 \mathrm{~A}$. Subsequently, $\mu$ reverses and, therefore, the Zeeman energy falls from $\mu_{0} \mu H_{K}$ to $-\mu_{0} \mu H_{K}$ and the corresponding energy difference dissipates as heat. In the magnetization reversal event, the work done in one cycle of the ACMF ' $H_{a c} \sin (2 \pi f t)$ ' is 0 for $H_{a c}<<H_{K}$ and $4 \mu_{0} \mu H_{K}$ for $H_{a c} \geq H_{K}$. In the latter case, the heat dissipation from MNPs per unit weight during unit time, also known as specific loss power $P_{H}$ can be expressed as $4 \mu_{0} \mu H_{K} f \varphi^{-1}\left(4 \mu_{0} M_{S} H_{K} f \rho^{-1}\right)$, where $\varphi$ and $\rho$ are the weight and density of the MNPs, respectively. In short, the $P_{H}$ value increases from 0 to $4 \mu_{0} \mu H_{K} f \varphi^{-1}$ with increase of $H_{a c}$ and flattens out if $H_{a c}$ is strengthened above $H_{K}$. Thus, the guiding principle for maximizing $P_{H}$ is that $H_{a c}$ is adjusted to $H_{K}$ and the number of ACMF cycles is maximized. Unfortunately, because of the technical restrictions on the ACMF amplitude and physiological limitations, the hysteresis loss cannot be completely used. Figure $4 \mathrm{C}$ shows the schematic representation of a typical hyperthermia setup.

In smaller-sized magnetic nanoparticles $\left(K V \leq k_{B} T\right)$, the magnetization reversal of ' $\mu$ ' is caused by thermal fluctuation. The magnetization reversal in a zero-magnetic field is associated with Néel relaxation and Brownian rotation of the nanoparticles (Figure 4B) [53]. The Néel $\left(\tau_{N}\right)$ and Brownian $\left(\tau_{B}\right)$ relaxation times are given by [54]

$$
\begin{gathered}
\tau_{N}=\tau_{0} \exp \left[\frac{K V}{k_{B} T}\right] \\
\tau_{B}=\frac{3 \eta V_{H}}{k_{B} T}
\end{gathered}
$$

The Néel relaxation is controlled by anisotropy energy $(K V)$ of nanoparticles. Equation (6) for the Brownian rotation is directly related to hydrodynamic parameters such as the hydrodynamic volume $\left(V_{H}\right)$ and the viscosity of the medium $(\eta)$.

If Néel relaxation and Brownian rotation occur in parallel, the effective relaxation time $\tau$ is given by [54]

$$
\begin{gathered}
\frac{1}{\tau}=\frac{1}{\tau_{B}}+\frac{1}{\tau_{N}} \\
\text { Hence, } \tau=\frac{M_{S}}{2 \gamma_{0} K^{3 / 2}}\left(\frac{\pi k_{B} T}{V}\right)^{1 / 2} \exp \left(\frac{K V}{k_{B} T}\right)
\end{gathered}
$$

For superparamagnetic nanoparticles, $\tau$ is determined only by $\tau_{N}$ because it decreases exponentially with decreasing the nanoparticles volume, while the decrease of $\tau_{B}$ is directly proportional to $V_{H}$. Further, for small $H_{a c}$, a linear response of the thermodynamic equilibrium state of the 
superparamagnetic nanoparticles (i.e., ACMF driven reversals) can be considered. In this case, the average of out-of-phase component of AC susceptibility $\chi^{\prime \prime}$ can be expressed as follows,

$$
\chi^{\prime \prime}=\frac{\mu_{0} \mu^{2}}{3 k_{B} T} \times \frac{\omega \tau}{1+(\omega \tau)^{2}}
$$

Consequently, the susceptibility loss occurs, and the corresponding specific loss power $P$ is expressed as [54].

$$
P=\pi \mu_{0} \chi^{\prime \prime} . H_{a c}^{2} \cdot f \cdot \rho^{-1}=\frac{\pi \mu_{0}^{2} \mu^{2} H_{a c}^{2}}{3 \rho k_{B} T} \frac{2 \pi f^{2} \tau}{\left[1+(2 \pi f \tau)^{2}\right]}
$$

Equation (10) indicates that $P$ increases in proportion to $f^{2}$ in the low frequency range $2 \pi f \ll \tau$, whereas, it flattens out at $\pi \mu_{0}^{2} \mu^{2} H_{a c}^{2} / 3 \rho k_{B} T$ even though $f$ is increased further in the high frequency range $2 \pi f \gg \tau$. Thus, the guiding principle for maximizing the specific loss power in the superparamagnetic regime is that $f$ can be fine-tuned to $\tau^{-1}$ and $H_{a c}$ can be maximized (Figure 4D-F). Further, from the above equation 8 and 10, it is evident that the increased $M_{S}$ values lead to a higher $P$ and hence metallic nanoparticles including $\mathrm{Fe}$, Co and $\mathrm{FeCo}\left(M_{S}\right.$ in the range of 150-220 emu/g) are suitable heating mediators, but they have not been considered for their cytotoxicity and poor stability in physiological environment. The heating activity of MNPs also need fine-tuning of the magnetic anisotropy constant $K$, it shifts the critical MNPs size that corresponds to the maximum $P$ to a lower value. However, smaller-sized MNPs possess the low moment and, hence they can exhibit poor heating activities. In short, an ideal material in the superparamagnetic regime would have a high $M_{S}$ and intermediate $K$ value.

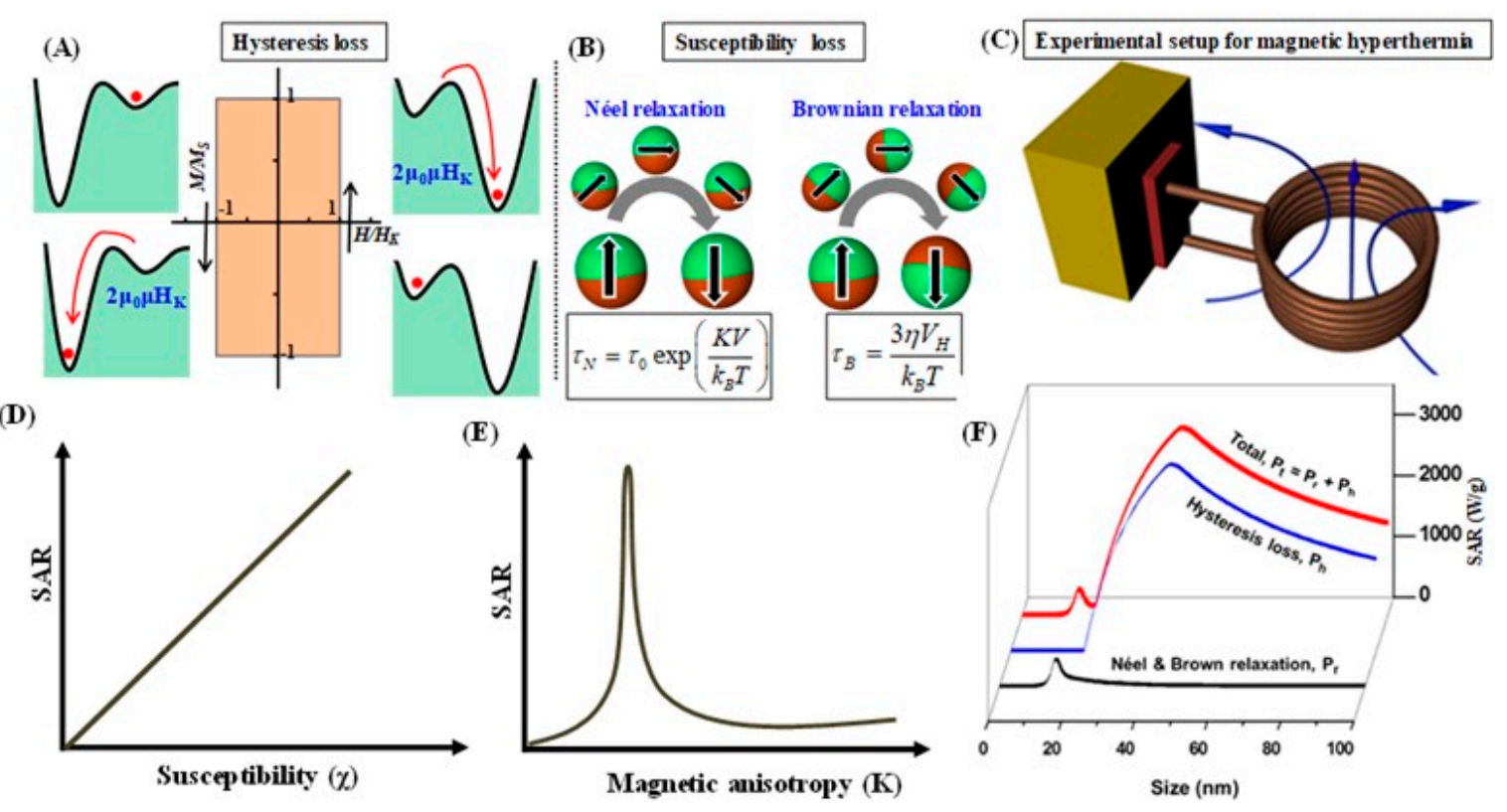

Figure 4. (A) Schematic view of the hysteresis loss in a ferromagnetic nanoparticle. Hysteresis loss in one cycle of ACMF is related to the area of the hysteresis loop and the Zeeman energy in magnetic field [56,57]. (B) Susceptibility loss given by the out-of-phase component of AC susceptibility is associated to the nanoparticle's relaxation. As demonstrated in the schematic, in Néel relaxation, the magnetic moment shown by the black arrow reverses (the particle does not rotate), while in Brownian relaxation, the particle (the sphere) rotates as a whole. (C) Schematic view of a typical hyperthermia setup. The variation of SAR based on (D) susceptibility $(\chi)$ and (E) magnetic anisotropy (K). (F) Size dependent SAR resulting from the susceptibility loss and the hysteresis loss [55]. 
The amount of heat generated by MNPs is usually quantified in terms of the specific absorption rate (SAR), given by [21]

$$
S A R=\frac{C}{m}\left(\frac{d T}{d t}\right)
$$

where $C$ is the specific heat of the colloid (i.e., for water, this value is $\left.4.18 \mathrm{~J} \mathrm{~g}^{-1} \mathrm{C}^{-1}\right), \mathrm{d} T / \mathrm{d} t$ is the initial slope of the temperature versus time graph, and $m$ is mass of magnetic material $(\mathrm{mg} / \mathrm{ml})$ in the suspension. As such, both the susceptibility loss and the hysteresis loss are strongly dependent on the MNPs size, and the SAR can show two maxima as shown in Figure 4F [55]. The $1^{\text {st }}$ peak in the superparamagnetic regime is related to the resonance condition $\left(2 \pi f \sim \tau^{-1}\right)$ and $2^{\text {nd }}$ peak in the ferromagnetic regime is attributed to the hysteresis loss. In addition, in both regimes a high $M_{S}$ is required to further optimize the SAR values, which will be discussed later in the Section 3.

\subsubsection{Effect of Curie Temperature $\left(T_{C}\right)$}

One of the most important restrictions of magnetic hyperthermia treatment is the risk of overheating in healthy tissues. A direct approach for overcoming this issue is to make the nanoparticles self-controlled, which can be realized by taking advantage of the MNPs' Curie temperature $\left(T_{C}\right)$ and adjusting the $T_{C}$ to the therapeutic temperature $\left(42-45^{\circ} \mathrm{C}\right)$. When the temperature increases above the $T_{C}$, the MNPs lose their ferromagnetic properties and instead shows paramagnetic behavior. Thus, the induction heating is immediately suppressed above the $T_{C}$. Recently, this phenomenon has been used to formulate ferrite-based self-controlled heating mediators, mainly the mixed ferrites such as $\mathrm{Zn}_{\mathrm{x}} \mathrm{Fe}_{3-\mathrm{x}} \mathrm{O}_{4}, \mathrm{MnZnFe}_{2} \mathrm{O}_{4}, \mathrm{MgFe}_{2} \mathrm{O}_{4}$, etc. [58-61].

The Curie temperature of a magnetic spinel ferrite can be assessed by the strength of exchange interactions between magnetic moments in the octahedral $\left(O_{h}\right)$ and the tetrahedral $\left(T_{d}\right)$ sublattices. The exchange interactions in ferrites are mediated by intermediating oxygen $p$-orbitals, known as super-exchange interactions. Thus, the $T_{C}$ can be adjusted by controlling compositions (i.e., magnetic moments of cations in two sublattices) and the distance between cations ions. Table 1 lists several spinel ferrite nanoparticles in which $T_{C}$ is adjusted by alteration in chemical composition via doping suitable amount of magnetic or nonmagnetic elements. Despite having the $T_{C}$ in the therapeutic temperature range, a high $M_{S}$ and moderate $K$ are required to obtain high SAR values. Thus, only a few of the ferrites $\left(\mathrm{Zn}_{x} \mathrm{Fe}_{3-\mathrm{x}} \mathrm{O}_{4}, \mathrm{MnZnFe}_{2} \mathrm{O}_{4}, \mathrm{MgFe}_{2} \mathrm{O}_{4}\right)$ have shown promising heating activities after adjusting their Curie temperature values to the required therapeutic limit.

Table 1. $T_{C}, M_{S}$ and SAR values of different mixed ferrite nanoparticles.

\begin{tabular}{llllll}
\hline Compound & MNPs Size & $T_{C}$ & $M_{S}$ & SAR & Ref. \\
\hline $\mathrm{Mg}_{1.37} \mathrm{Fe}_{1.26} \mathrm{Ti}_{0.37} \mathrm{O}_{4}$ & $>100 \mathrm{~nm}$ & $46{ }^{\circ} \mathrm{C}$ & $8 \mathrm{emu} / \mathrm{g}$ & $3.9 \mathrm{~W} / \mathrm{g}$ & {$[61]$} \\
\hline $\mathrm{Zn}_{0.9} \mathrm{Fe}_{2.1} \mathrm{O}_{4}$ & $11 \mathrm{~nm}$ & $93{ }^{\circ} \mathrm{C}$ & $12 \mathrm{emu} / \mathrm{g}$ & $36 \mathrm{~W} / \mathrm{g}$ & {$[58]$} \\
\hline $\mathrm{MnFe}_{1.4} \mathrm{Ag}_{0.6} \mathrm{O}_{4}$ & $4-7 \mathrm{~nm}$ & $87{ }^{\circ} \mathrm{C}$ & $\sim 15 \mathrm{emu} / \mathrm{g}$ & - & {$[62]$} \\
\hline $\mathrm{Zn}_{0.6} \mathrm{Cu}_{0.4} \mathrm{Fe}_{2} \mathrm{O}_{4}$ & $460 \mathrm{~nm}$ & $32{ }^{\circ} \mathrm{C}$ & - & - & {$[59]$} \\
\hline $\mathrm{Mn}_{0.8} \mathrm{Zn}_{0.2} \mathrm{Fe}_{2} \mathrm{O}_{4}$ & $20-25 \mathrm{~nm}$ & $42-45^{\circ} \mathrm{C}$. & $67 \mathrm{emu} / \mathrm{g}$ & $110 \mathrm{~W} / \mathrm{g}$ & {$[63]$} \\
\hline $\mathrm{Zn}_{\mathrm{x}} \mathrm{Fe}_{3-\mathrm{x}} \mathrm{O}_{4}(0.01 \leq \mathrm{x} \leq 0.8)$ & $3-10 \mathrm{~nm}$ & $\sim 125^{\circ} \mathrm{C}$ & $35-65 \mathrm{emu} / \mathrm{g}$ & & {$[60]$} \\
\hline
\end{tabular}

\section{Enhancing Inductive Heating by Engineering the Magnetic Nanostructures}

\subsection{Size Effects}

In the past few years, significant attention has been devoted to synthesizing monodispersed magnetic nanoparticles with precise control over their size, composition and shape. While several synthetic strategies have been proposed to synthesize ferrite nanoparticles, the high-temperature solution phase methods appear to be the most interesting because it permits a good control over 
the size and the morphology of the nanoparticles $[33,64]$. In this approach, the high-temperature reaction of iron (III) acetylacetonate or iron oleate in the presence of oleic acid, and/or oleylamine leads to the formation of $\mathrm{Fe}_{3} \mathrm{O}_{4}$ nanoparticles $[65,66]$. A brief pictorial detail of the synthesis procedure is shown in Figure 5. An exciting development in the synthesis of monodispersed iron oxide NPs was demonstrated by Park et al. [33]. In a typical reaction, Fe-oleate complex was prepared by reacting iron chloride with sodium oleate, which was thermally decomposed into monodispersed $\mathrm{Fe}_{3} \mathrm{O}_{4} \mathrm{NPs}$ in octadecene at $320^{\circ} \mathrm{C}$. With the help of the seed-mediated growth, $\mathrm{Fe}_{3} \mathrm{O}_{4} \mathrm{NPs}$ with 4 to $13 \mathrm{~nm}$ diameters were obtained [64]. Later, $\mathrm{Xu}$ et al. found that by changing the heating conditions, and ratios of oleylamine and oleic acid, the size of $\mathrm{Fe}_{3} \mathrm{O}_{4}$ NPs can be tuned from 14 to $100 \mathrm{~nm}$ [67]. Recently, oleylamine was used as a multitasking agent, acting as a solvent, and reducing and surface functionalizing agents, to prepare monodispersed $\mathrm{Fe}_{3} \mathrm{O}_{4}$ NPs with a reasonably large magnetization value [68-71]. The experiment confirms that the presence of excess amount of oleylamine offers an adequately strong reductive environment for the Fe-precursor and leads to the formation of $\mathrm{Fe}_{3} \mathrm{O}_{4}$ NPs at a reasonably low temperature of $240{ }^{\circ} \mathrm{C}$. Figure 6A shows the representative TEM micrographs of monodispersed $\mathrm{Fe}_{3} \mathrm{O}_{4}$ nanoparticles of size ranging from 6 to $24 \mathrm{~nm}$, prepared by thermolysis of Iron(III) acetylacetonate in oleic acid and oleylamine [71]. These synthesis methods were also extended to formulate $\mathrm{MFe}_{2} \mathrm{O}_{4}(\mathrm{M}=\mathrm{Co}, \mathrm{Ni}$, and $\mathrm{Mn}) \mathrm{NPs}$.

(A)
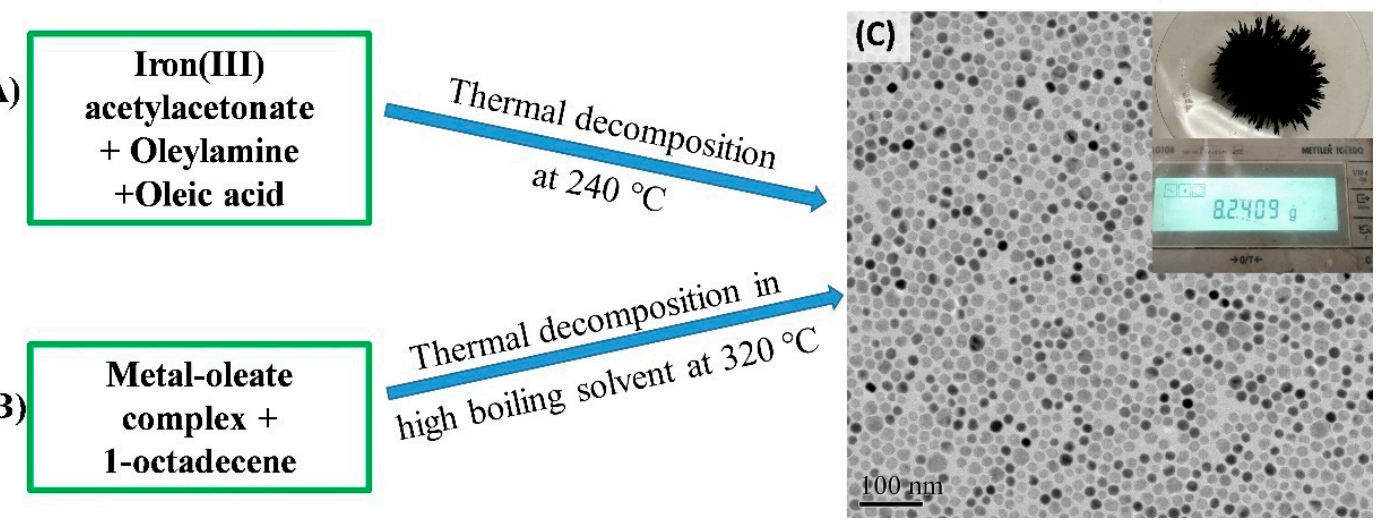

Figure 5. Schematic illustration of two simple approaches have been widely used to synthesize monodispersed iron oxide NPs: (A) Thermal decomposition of iron-precursor in oleylamine and oleic acid as surfactant and (B) thermal decomposition of metal-organic complex in octadecene. (C) Representative TEM image of $12 \mathrm{~nm} \mathrm{Fe}_{3} \mathrm{O}_{4}$ NPs prepared in large scale from the decomposition of iron (III) acetylacetonate. The inset is a digital photograph showing $8.2 \mathrm{~g}$ of the $\mathrm{Fe}_{3} \mathrm{O}_{4} \mathrm{NPs}$ produced in a single batch [71].

The size-dependent characteristics of MNPs are magnetization and blocking temperature, and their values increase with the increase of NPs size (Figure 6). An inherent characteristic of superparamagnetic nanoparticles is that they possess a magnetically disordered spin structure at the surface, because of the reduced exchange coupling between spins at the surface (due to the cations vacancy, ligands and high surface energy). Thus, magnetic nanoparticles are considered to be core-shell structures that are composed of a magnetically ordered core and a disordered shell that is known as spin canting/spin disorder [72,73]. The magnetization as a function of nanoparticles size ' $d$ ' and disordered surface layer thickness ' $t$ ' is described as $M_{S}=M_{B u l k}[1-(6 t / d)]$ [74]. The size effect on the $M_{S}$ value has been observed in both ferrimagnetic and ferromagnetic nanoparticles. Figure $6 \mathrm{~B}$ shows sharp increases of $M_{S}$ value with increase in the size of $\mathrm{Fe}_{3} \mathrm{O}_{4}$ nanoparticles prepared via thermal decomposition of Fe-precursor. The calculated spin disorder layer thickness is around 0.2 to $0.5 \mathrm{~nm}$. However, the surface spin disorder effect increases with decreasing the particle size due to the higher surface-to-volume ratio. Therefore, the $M_{s}$ value approaches to the bulk value $\left(92 \mathrm{emu} \mathrm{g}^{-1}\right)$ with the increase of $\mathrm{Fe}_{3} \mathrm{O}_{4}$ NPs size [75]. 

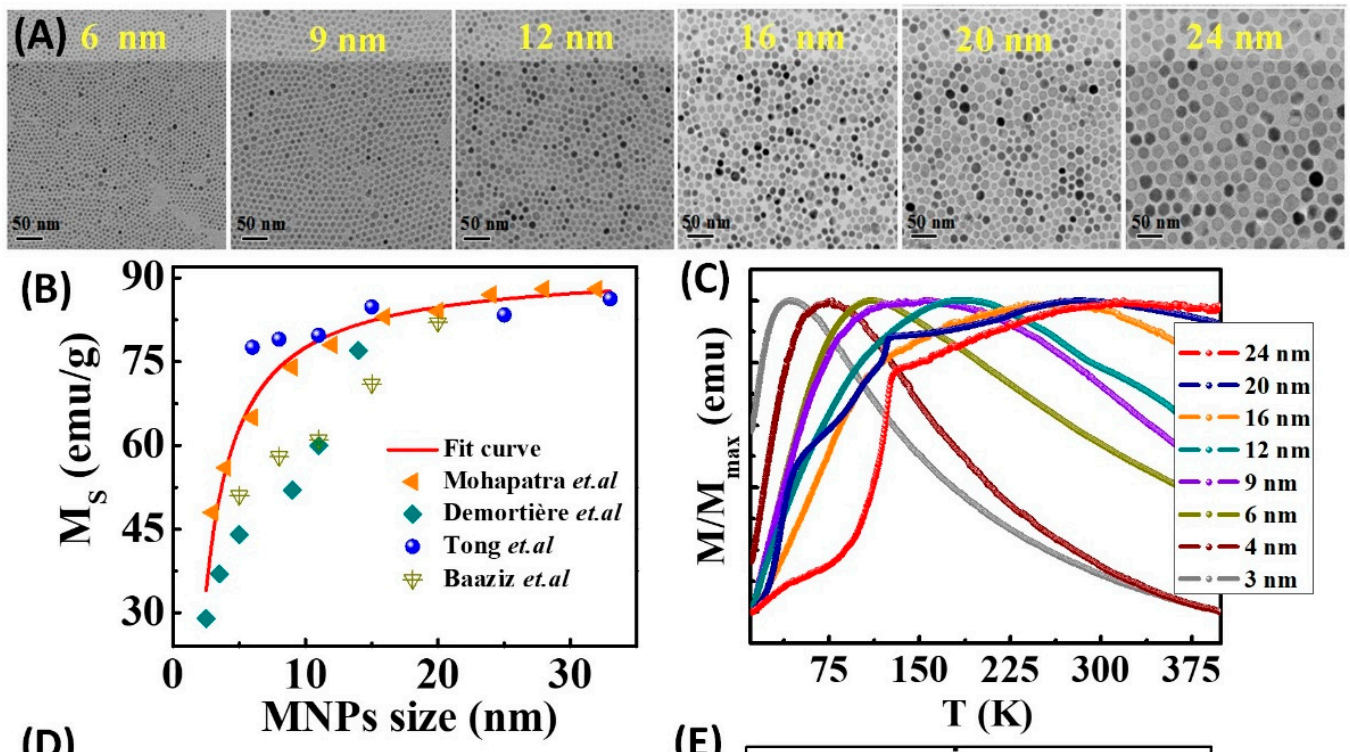

(D)
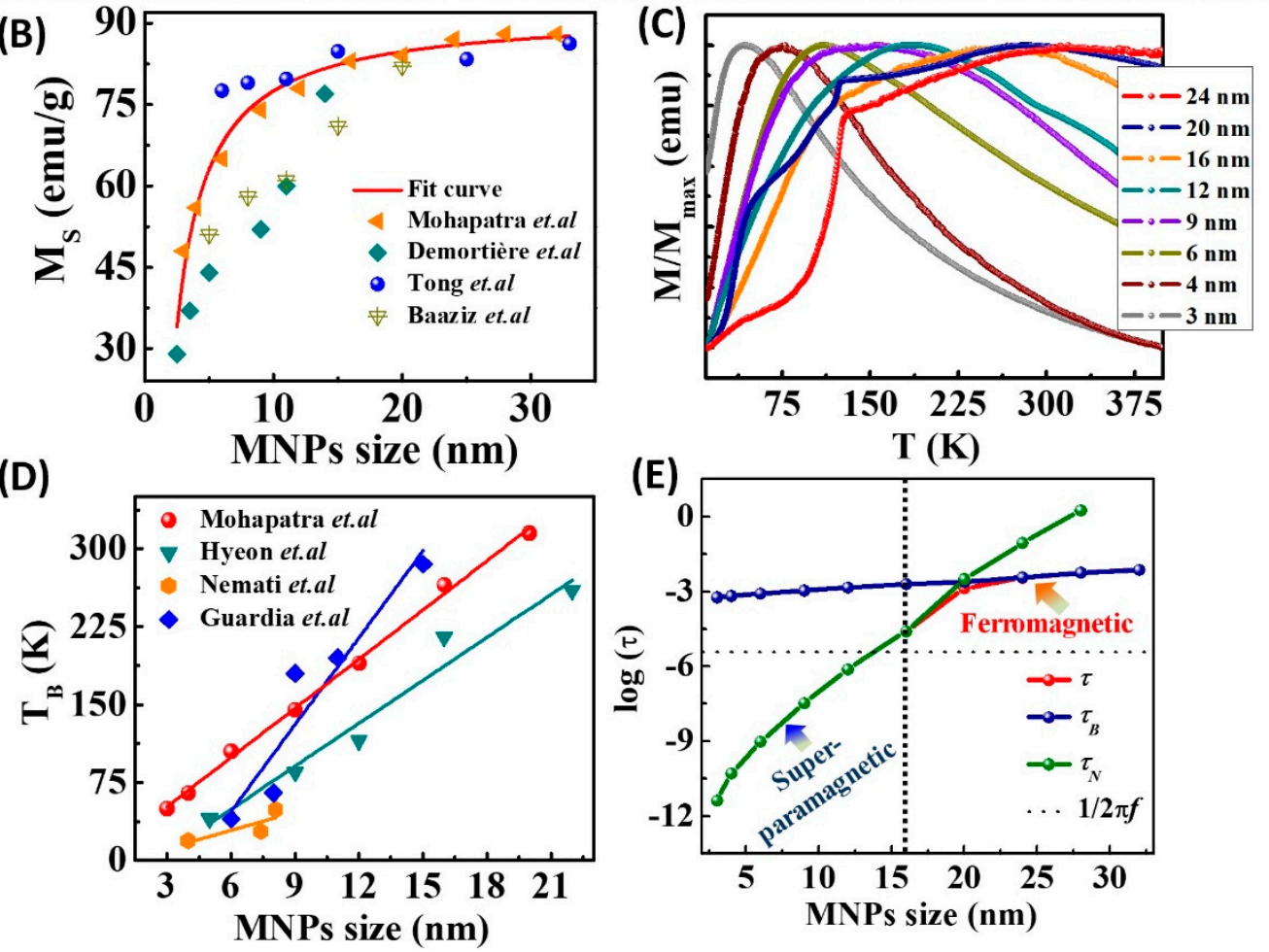

Figure 6. (A) The TEM micrographs of differently sized $\mathrm{Fe}_{3} \mathrm{O}_{4}$ nanoparticles. (B) A relationship between $M_{S}$ value and the nanoparticle size [71,76-78]. (C) The zero-field cooled (ZFC) magnetization curves of different sized $\mathrm{Fe}_{3} \mathrm{O}_{4}$ nanoparticles [71]. (D) Blocking temperature $\left(T_{B}\right)$ versus nanoparticle size ' $d$ ' $[33,71,72]$. (E) The variation of Neel relaxation time and Brownian relaxation time with $\mathrm{Fe}_{3} \mathrm{O}_{4}$ nanoparticles size [71].

The blocking behavior in MNPs is observed when the thermal energy $\left(k_{B} T\right)$ exceeds the anisotropy energy $\left[E_{a}=K_{\text {eff }} V \sin ^{2} \theta\right.$, where $K_{\text {eff }}$ is the sum of several terms such as magnetocrystalline anisotropy, shape anisotropy, surface anisotropy, and inter-particle coupling between nanoparticles]. Since anisotropy energy is directly proportional to the volume of the nanoparticles, the blocking temperature $\left(T_{B}\right)$ increases with the increase in the size of nanoparticles. The zero-field-cooled magnetization $\left(M_{Z F C}\right)$ curves (at applied field $100 \mathrm{Oe}$ ) for the $\mathrm{Fe}_{3} \mathrm{O}_{4}$ nanoparticles are shown in Figure $6 \mathrm{C}$. The obtained $T_{B}$ values for different sized $\mathrm{Fe}_{3} \mathrm{O}_{4}$ nanoparticles indicates a linear increasing trend of $T_{B}$ with the size of MNPs as shown in Figure 6D. The effective anisotropy constant can be calculated using the Neél law $\left(T_{B}=K_{\text {eff }} V / 25 k_{B}\right)$. The obtained $K_{\text {eff }}\left(1.1 \times 10^{6}\right.$ to $\left.1.5 \times 10^{4} \mathrm{~J} \mathrm{~m}^{-3}\right)$ values are much larger than that for bulk magnetite $\left(1.35 \times 10^{4} \mathrm{~J} \mathrm{~m}^{-3}\right)$ [40]. The high $K_{\text {eff }}$ value is due to the surface anisotropy contribution from the disordered surface spins layer of the nanoparticles and interparticle interactions between neighbouring nanoparticles. The ZFC magnetization for the 20 and $24 \mathrm{~nm}$ sized $\mathrm{Fe}_{3} \mathrm{O}_{4} \mathrm{NPs}$ showed a sharp drop at $120 \mathrm{~K}$. This is a characteristic transition of pristine magnetite phase, known as the Verwey transition. Below the Verwey transition temperature, the magnetic easy axis switches from the $\langle 111\rangle$ to the $\langle 100\rangle$ direction, which leads to the reduction of $M_{Z F C}$. More importantly, the Verwey transition is extremely sensitive to oxidation, in fact it disappears when off-stoichiometry parameter $\delta$, defined as $\mathrm{Fe}_{3(1-\delta)} \mathrm{O}_{4}$, is larger than 1\% [79]. 
The Néel relaxation time and the Brownian relaxation time can be calculated using effective magnetic anisotropy constant $\left(K_{e f f}\right)$ and the hydrodynamic diameter, respectively. The obtained Brownian, Néel and effective relaxation times for MNPs are plotted as a function of size in Figure 6E. Note that the $\tau_{N}$ value depends more strongly on the MNP size than the $\tau_{B}$ value. Moreover, the $\tau_{N}$ value can be further tuned by controlling the composition of MNPs. Above the superparamagnetic critical size limit, the Brownian relaxation dominates. As the $\tau_{B}$ value is proportional to the $V_{H}$ of the particles, it can be increased by coating the MNPs with a long-chain surfactant molecule. The scaling relationship between magnetic properties and MNPs size is schematically illustrated in Figure 7. Since the hyperthermia heating efficiency is dependent on the $M_{S}$ and $K_{\text {eff }}$ of the MNPs, the size control synthesis of MNPs will result in enhanced hyperthermia effects for an optimum size.

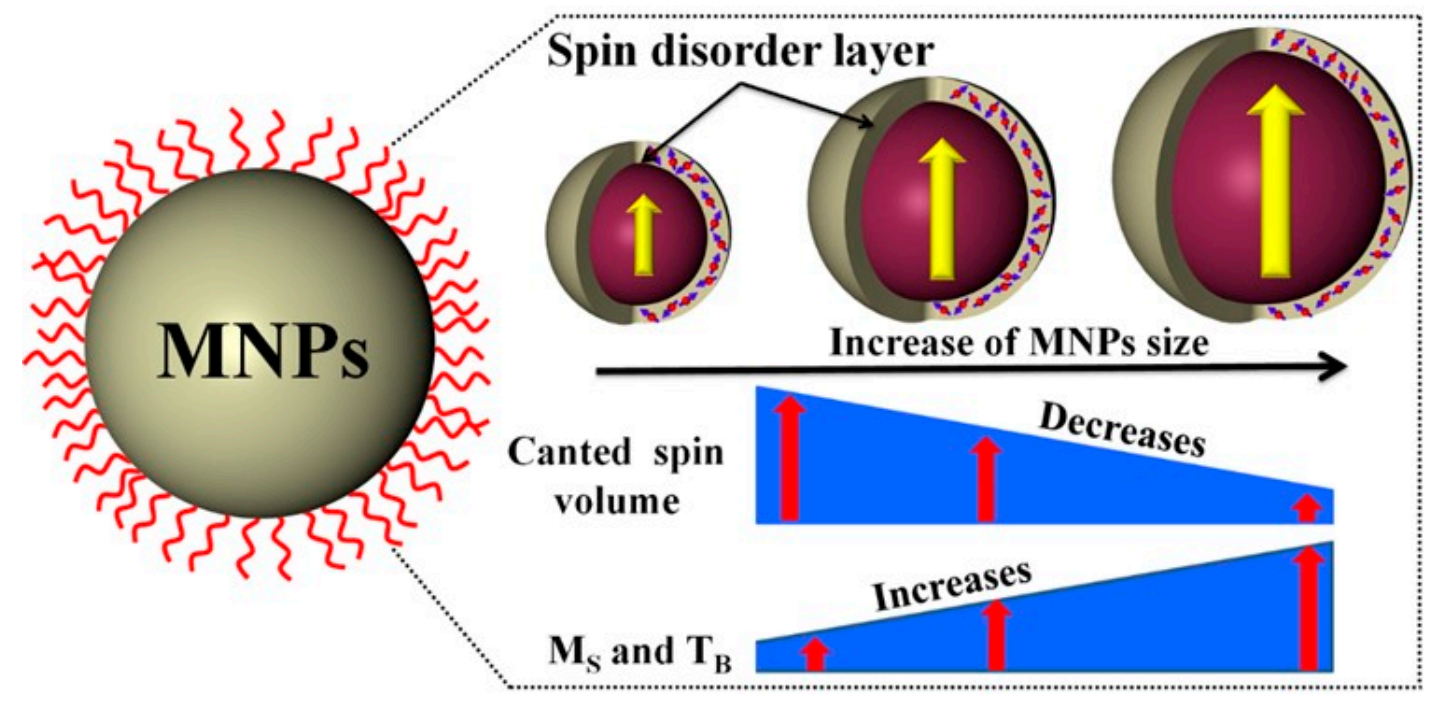

Figure 7. Schematic representation of the variation of spin-canting effect, saturation magnetization, and blocking temperature with the MNPs size.

It is known that according to linear response theory (LRT, Equation (10)), the SAR of superparamagnetic particles is proportional to the applied ACMF amplitude and frequency. Furthermore, the maximum absorption of magnetic energy occurs when the effective relaxation time of MNPs is close to the frequency of the applied ACMF $(\omega \tau \approx 1)$. This indicates that for a given ACMF frequency $(\omega=2 \pi f)$ there is an optimal size that resonates well with the applied ACMF. Figure 8A illustrates the size dependency of loss power for different MNPs [80]. As can be seen, the maximum value for heating efficiency occurs at the resonance condition when $\omega \tau \approx 1$. Further, the relaxation time $\tau$ is inversely related to the effective magnetic anisotropy and is determined by the MNPs' structure. Thus, the critical size corresponding to the maximum loss power is smaller for high magnetic anisotropy materials such as FePt $\left(206 \mathrm{~kJ} / \mathrm{m}^{3}\right), \mathrm{Co}\left(412 \mathrm{~kJ} / \mathrm{m}^{3}\right)$, and Fe $\left(48 \mathrm{~kJ} / \mathrm{m}^{3}\right)$ compared to $\mathrm{Fe}_{3} \mathrm{O}_{4}\left(9 \mathrm{~kJ} / \mathrm{m}^{3}\right)$. In the superparamagnetic regime, Vreeland et al. observed that for an ACMF of $H_{a c}=36.5 \mathrm{kA} / \mathrm{m}$ and $f=341 \mathrm{kHz}$, the optimum size corresponding to maximum SAR is around $22 \mathrm{~nm}$, which matches the theoretical prediction of the LRT (Figure 8B) [81]. Moreover, the heating activity in superparamagnetic regime is mainly ascribed to the Néel relaxation and thus the optimum SAR is achieved at the resonance condition $\left(\omega \tau_{N} \approx 1\right)$. Most experimental studies on the size dependency of heating efficiency in the superparamagnetic regime reported that the maximum SAR can be achieved with iron oxide NPs of size $\sim 15$ to $22 \mathrm{~nm}$, depending on the ACMF amplitude and frequency [82-86]. 
(A)

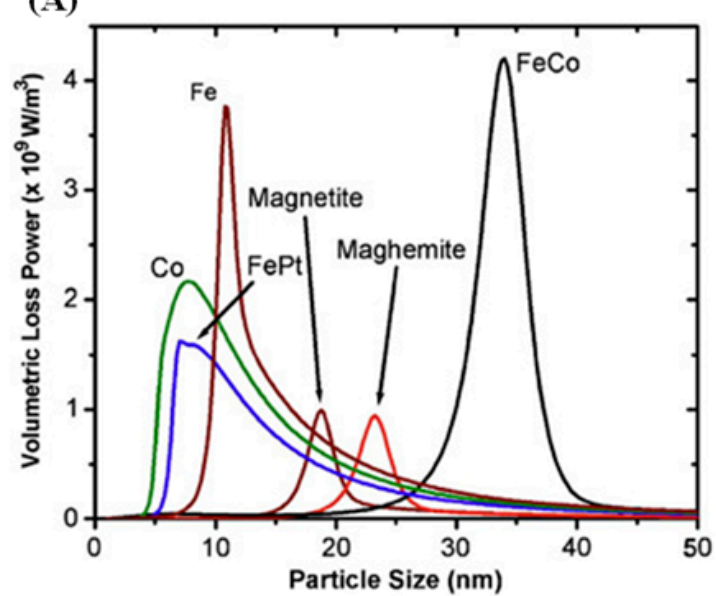

(C)

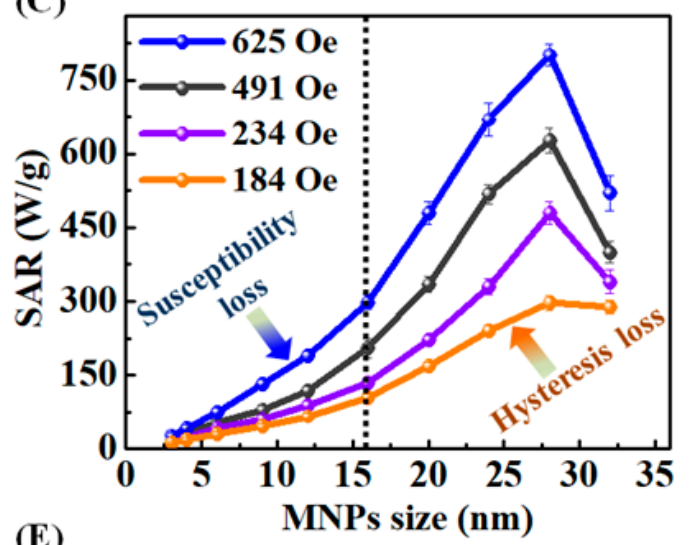

(E)

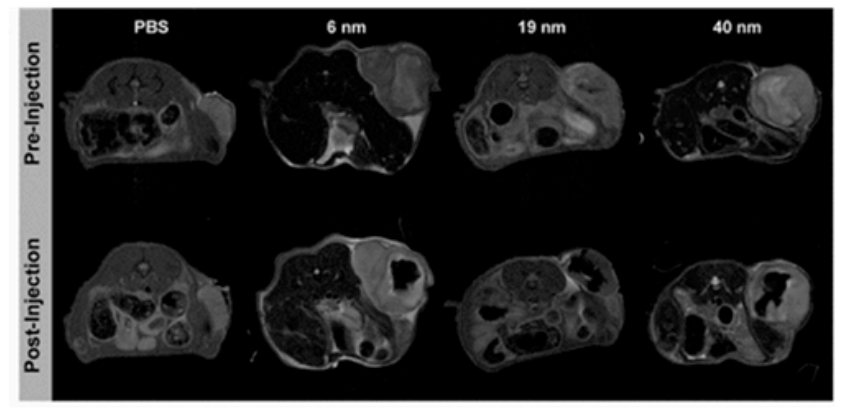

(B)

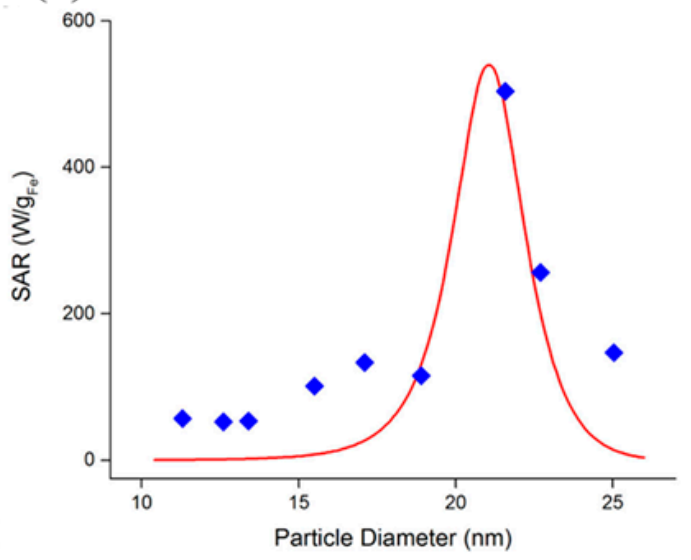

(D)

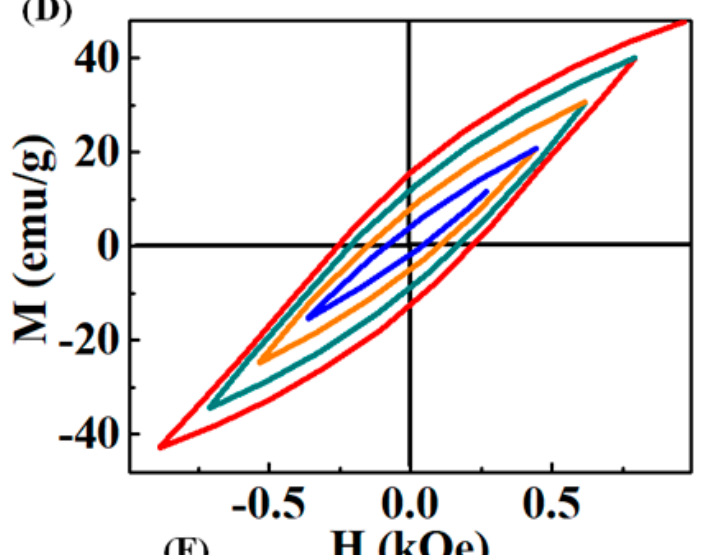

(F)

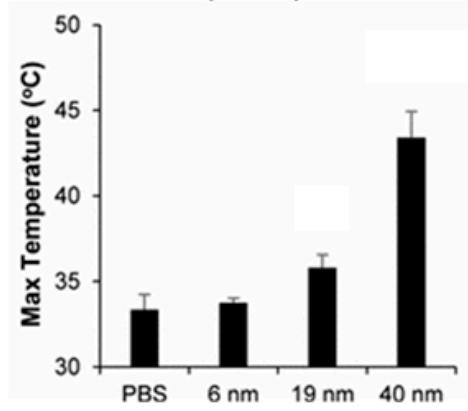

Figure 8. (A) Depicts volumetric loss power versus particle size for various MNPs dispersed in water at $10 \%$ particle concentration in ACMF $\left(f=300 \mathrm{kHz}, H_{a c}=50 \mathrm{mT}\right)$ [80]. (B) The theoretical (red) and experimental (blue) SAR values of $\mathrm{Fe}_{3} \mathrm{O}_{4}$ nanoparticles with different diameters [81]. (C) Depicts the variation of the SAR values as a function of MNP size at different amplitudes for the ACMF field (184-625 Oe) [71]. (D) Shows the room temperature minor $\mathrm{M}(\mathrm{H})$ loops of $28 \mathrm{~nm}$ MNPs at various magnetic fields: 300 (blue), 500 (orange), 700 (green) and 900 Oe (red) [71]. (E) MRI images of the cross section of the mouse bodies before and after infusion of 6, 19 and $40 \mathrm{~nm} \mathrm{Fe}_{3} \mathrm{O}_{4}$ nanoparticles dispersion and $(\mathrm{F})$ Maximum temperature reached during $1 \mathrm{~h}$ of heating [76].

Nevertheless, the recent results are contradictory with the LRT model showing that some of the highest SAR values were observed in MNPs with particle size $>20 \mathrm{~nm}$. Tong et al. have shown that both in the superparamagnetic and ferromagnetic regime the SAR values increased monotonically with nanocrystal size and the most dramatic increases by 50-fold occurred between 11 and $33 \mathrm{~nm}$ sized $\mathrm{Fe}_{3} \mathrm{O}_{4}$ nanoparticles [76]. In fact, the maximum SAR values attended are 1026 and $2560 \mathrm{~W} / \mathrm{g}$ of Fe at 9.35 and $20.7 \mathrm{kA} / \mathrm{m}$ field strength, respectively for $40 \mathrm{~nm} \mathrm{Fe}{ }_{3} \mathrm{O}_{4}$ nanoparticles. A similar size dependence trend in the SAR values also has been noticed recently by Mohapatra et al. [71]. Figure 8C 
shows the relative heating performance of $\mathrm{Fe}_{3} \mathrm{O}_{4}$ nanoparticles in the 3-32 nm size range measured under applied ACMF amplitudes of 184, 324, 491 and 625 Oe at a fixed frequency of $265 \mathrm{kHz}$. It can be seen from the figure that the SAR increases with the increase of nanoparticle size and attains a maximum value at a particle size of $28 \mathrm{~nm}$, then the value decreases with further increase of the particles size. Remarkably, the increasing trend of the SAR has two different scenarios with respect to the MNPs size. The SAR value increases from 27-298 W/g of $\mathrm{Fe}_{3} \mathrm{O}_{4}$ (with $H_{a c}=625 \mathrm{Oe}$ ) with the increases of MNPs size from 3-16 nm and with further increase of the MNPs size it increases rapidly. The comparison between the LRT model prediction and the experimental SAR values (Figure 8B) indicates that the LRT model is applicable only for MNPs size $\leq 16 \mathrm{~nm}$ (i.e., the superparamagnetic regime). In theory, increasing the MNPs size above $16 \mathrm{~nm}$ can suppress the susceptibility loss due to the particle moment blocking, and consequently the SAR should reduce. Instead, the SAR value increases sharply with the increase of MNPs size from 16-28 nm. The fast increase of the SAR (above $16 \mathrm{~nm}$ ) values is due to the combined effect of susceptibility loss and hysteresis loss. In the ferromagnetic regime, the amount of dissipated heat as a result of hysteresis loss is proportional to the area under the hysteresis loop, which increases with the increase of MNPs size [87-89]. According to the dynamic hysteresis model, the quasi-static hysteresis loops change with the field strength and the frequency of the ACMF. In particular, the hysteresis loop enlarges with the frequency, the magnetic field (Figure 8D) and MNPs size. The improvement of the hysteresis loop area results in the enhanced hysteresis loss in the larger sized MNPs.

To illustrate the potential applications of ferromagnetic MNPs in cancer treatment, Tong et al., tested 6, 19 and $40 \mathrm{~nm}$ MNPs on the mouse xenograft tumor model for glioblastoma multiforme (GBM) [76]. GBM is an aggressive and invasive brain cancer, thus surgical resection will be complicated. An alternative treatment strategy is local hyperthermia treatment. $T_{2}$-weighted magnetic resonance (MR) images acquired before and after injection of MNPs (50 $\mu \mathrm{g}$ of Fe) display the sharp contrast of the tumor region (see Figure 8E). A more accurate dosimetry of the spatial temperature profiles during heating treatment are obtained by in vivo quantitative MR imaging of MNPs. Following imaging, the mice are exposed to an ACMF $(9.35 \mathrm{kA} / \mathrm{m}, 325 \mathrm{kHz})$ for $1 \mathrm{~h}$. The tumors injected with the $6 \mathrm{~nm}$ MNPs did not show a temperature increase compared to the control, whereas the 19 and $40 \mathrm{~nm}$ MNPs showed a temperature increase of 2.5 and $10.1{ }^{\circ} \mathrm{C}$, respectively (Figure $8 \mathrm{~F}$ ). The $40 \mathrm{~nm}$ MNPs are able to reach $43.4 \pm 1.5^{\circ} \mathrm{C}$ during the course of the treatment, which could be sufficient for many cancer thermal therapies.

\subsection{Composition Effects}

Compositional modification in MNPs via the substitution of $\mathrm{M}^{2+}(\mathrm{M}=\mathrm{Mn}, \mathrm{Co}, \mathrm{Ni}$ and $\mathrm{Zn})$ cations have significantly altered the magnetic properties. For example, the $\mathrm{Fe}_{3} \mathrm{O}_{4} \mathrm{NPs}$ have an inverse spinel structure with $\mathrm{Fe}^{2+}$ and $\mathrm{Fe}^{3+}$ occupying octahedral ' $\mathrm{O}_{h}$ ' sites aligned parallel to the external magnetic field and $\mathrm{Fe}^{3+}$ in the tetrahedral ' $T_{d}$ ' sites aligned antiparallel to the field. Since the magnetic moment of $\mathrm{Fe}^{3+}$ and $\mathrm{Fe}^{2+}$ with a high spin state are $5 \mu_{\mathrm{B}}$ and $4 \mu_{B}$, respectively, the total magnetic moment per formula unit $\left(\mathrm{Fe}^{3+}\right)_{T d}\left(\mathrm{Fe}^{2+} \mathrm{Fe}^{3+}\right)_{O_{h}} \mathrm{O}_{4}$ is approximately $4 \mu_{B}$. The substitution of $\mathrm{M}^{2+}$ cations with magnetic moment $5 \mu_{B}(\mathrm{Mn}), 3 \mu_{B}(\mathrm{Co})$ and $2 \mu_{B}(\mathrm{Ni})$ for $\mathrm{O}_{h} \mathrm{Fe}^{2+}$ leads to changes in the net magnetization per mass of magnetic atoms: $110 \mathrm{emu} / \mathrm{g}\left(\mathrm{MnFe}_{2} \mathrm{O}_{4}\right), 101 \mathrm{emu} / \mathrm{g}\left(\mathrm{FeFe}_{2} \mathrm{O}_{4}\right)$, $99 \mathrm{emu} / \mathrm{g}\left(\mathrm{CoFe}_{2} \mathrm{O}_{4}\right)$, and $85 \mathrm{emu} / \mathrm{g}\left(\mathrm{NiFe}_{2} \mathrm{O}_{4}\right)$, respectively [90]. The composition and size have been controlled precisely to understand their effect on magnetic properties (Figure 9A). As expected, the $M_{S}$ values of similar sized $\mathrm{MFe}_{2} \mathrm{O}_{4}(\mathrm{M}=\mathrm{Mn}, \mathrm{Fe}, \mathrm{Co}, \mathrm{Ni}$ and $\mathrm{Zn})$ nanoparticles strongly depend on the magnitude of the $\mathrm{M}^{2+}$ cation magnetic moment $\left(n \mu_{B}\right.$, where $n=5,4,3,2$ and 0 for $\mathrm{Mn}, \mathrm{Fe}, \mathrm{Co}, \mathrm{Ni}$ and $\mathrm{Zn}$, respectively) [91]. For instance, the $M_{S}$ values of $6 \mathrm{~nm}$ size $\mathrm{MnFe}_{2} \mathrm{O}_{4}$ nanoparticles is $71 \mathrm{emu} / \mathrm{g}$ which reduces as per the periodic arrangement to 65, 55 and 50 for $\mathrm{FeFe}_{2} \mathrm{O}_{4}, \mathrm{CoFe}_{2} \mathrm{O}_{4}$ and $\mathrm{NiFe}_{2} \mathrm{O}_{4}$ $\mathrm{NPs}$, respectively [92]. Interestingly, the $\mathrm{ZnFe}_{2} \mathrm{O}_{4}$ nanoparticles have saturation magnetization of $40 \mathrm{emu} / \mathrm{g}$ which indicates random magnetic ordering at the nanoscale $(6 \mathrm{~nm})$, which would otherwise be antiferromagnetic in the bulk regime [93]. Further, the $M_{S}$ values increase rapidly towards the bulk 
value as the nanoparticle size is increased. For example, the $2 \mathrm{~nm} \mathrm{MnFe}{ }_{2} \mathrm{O}_{4}$ nanoparticles have an $M_{S}$ value of $39 \mathrm{emu} / \mathrm{g}$, which increases to $86 \mathrm{emu} / \mathrm{g}$ (close to the magnetization value of $89 \mathrm{emu} / \mathrm{g}$ of bulk $\left.\mathrm{MnFe}_{2} \mathrm{O}_{4}\right)[94,95]$ as the size is increased to $16 \mathrm{~nm}$. This increasing trend in magnetization value is attributed to the decay in surface spin disorder effects with the increase of the particle size.

The blocking behavior of $\mathrm{MFe}_{2} \mathrm{O}_{4} \mathrm{NPs}$ is also strongly related to the composition as the magnetocrystalline anisotropy varies with the spin-orbit coupling strength of $\mathrm{M}^{2+}$ cations. Figure $9 \mathrm{~B}$ shows the size dependence blocking behavior of $\mathrm{MFe}_{2} \mathrm{O}_{4} \mathrm{NPs}$. The exchange coupled CoFe [92]. In contrast to the $\mathrm{Fe}_{3} \mathrm{O}_{4}$ nanoparticles, the $T_{B}$ value of $\mathrm{CoFe}_{2} \mathrm{O}_{4}$ nanoparticles is higher. The difference in $T_{B}$ values for the same size NPs of various transition metal $\left(\mathrm{M}^{2+}\right)$ substituted spinel nanostructure is related to the magnetocrystalline anisotropy. In magnetite, the $\mathrm{Fe}^{3+}$ cations (orbital angular momentum $\mathrm{L}=0$ ) evenly occupy the tetrahedral $\left(T_{d}\right)$ and octahedral $\left(O_{h}\right)$ sites and while $\mathrm{M}^{2+}\left(\mathrm{Fe}^{2+}\right)$ cations are only located in the octahedral $\left(O_{h}\right)$ sites. Thus, the magnetocrystalline anisotropy arises from the spin-orbit coupling strength of $\mathrm{M}^{2+}$ cations and this strength increases in an order like $\mathrm{Mn}^{2+}<\mathrm{Fe}^{2+}<\mathrm{Co}^{2+}[96]$. The stronger spin-orbit coupling of $\mathrm{Co}^{2+}$ ions lead to larger $T_{B}$ for $\mathrm{CoFe}_{2} \mathrm{O}_{4} \mathrm{NPs}$. Further, in contrast to other ferrites, $\mathrm{CoFe}_{2} \mathrm{O}_{4}$ NPs reveal a rapid increase of $T_{B}$ with size increase, which confirms the hypothesis of larger anisotropy (L-S coupling) energy for $\mathrm{CoFe}_{2} \mathrm{O}_{4}$ nanoparticles.

Recent work has shown that because of the large magnetocrystalline anisotropy constant $\left(K=2 \times 10^{5} \mathrm{~J} / \mathrm{m}^{3}\right)$ of cobalt, it can be used to effectively tune the magnetic properties through the controlled doping of $\mathrm{Co}$ in $\mathrm{Fe}_{3} \mathrm{O}_{4}, \mathrm{MnFe}_{2} \mathrm{O}_{4}$ and $\mathrm{ZnFe}_{2} \mathrm{O}_{4}$ nanoparticles [97-99]. A systematic adjustment of Co stoichiometry in $\mathrm{Co}_{x} \mathrm{Fe}_{3-\mathrm{x}} \mathrm{O}_{4}(x=0,0.1,0.3$ and 0.5$) \mathrm{NPs}$ from 0 to 0.5 results in an increase in magnetic anisotropy and coercivity with maximum value reached $x=0.5$ (see Figure 9C) $[99,100]$. The $M_{S}$ value of $\mathrm{Fe}_{3} \mathrm{O}_{4}$ nanoparticles is $86 \mathrm{emu} / \mathrm{g}$, and it is decreased to 82,78 and $77 \mathrm{emu} / \mathrm{g}$, respectively with the increase of $\mathrm{Co}^{2+}$ ion concentration due to the smaller magnetic moment of $\mathrm{Co}^{2+}\left(3 \mu_{B}\right)$ as compared to $\mathrm{Fe}^{2+}\left(4 \mu_{B}\right)$ [91]. Figure 9D shows the typical variation of $M_{S}$ value with modulation of the $\mathrm{Co}$ and $\mathrm{Zn}$ content in $\mathrm{Fe}_{3} \mathrm{O}_{4}$ nanoparticles. Interestingly, with the increasing $\mathrm{Zn}$ content in $\mathrm{Zn}_{\mathrm{x}} \mathrm{Fe}_{3-\mathrm{x}} \mathrm{O}_{4}$ ( $x$ from 0 to 0.6 ) nanoparticles, the $M_{S}$ value increases (from 84.5 to $91.9 \mathrm{emu} / \mathrm{g}$ ) and a further increase of $\mathrm{Zn}$ content, the $M_{S}$ value sharply decreases. The initial increase in $M_{S}$ with increasing $\mathrm{Zn}$ content is believed to be due to the cation distribution among $T_{d}$ and $\mathrm{O}_{h}$-sites in the spinel structure. When the nonmagnetic $\mathrm{Zn}^{2+}$ ion replaces the magnetic $\mathrm{Fe}^{3+}$ ions in $T_{d}$-site the net magnetic moment between $O_{h}$ and $T_{d}$ sites increases up to $x=0.6$ [101]. A further increase of $\mathrm{Zn}$ content above 0.6 can partially replace the $\mathrm{Fe}^{2+}$ ions and also impair the superexchange interaction between the magnetic ions at $O_{h}$ and $T_{d}$ sites, which causes a rapid decrease in the net magnetic moment.

Like the magnetic properties, the heating efficiency of MNPs is strongly related to the composition. In order to demonstrate the effect of composition on hyperthermia properties, we take $\mathrm{Co}_{\mathrm{x}} \mathrm{Fe}_{3-\mathrm{x}} \mathrm{O}_{4}$ nanoparticles as an example, since Co strongly alter the magnetic anisotropy. Figure 10A shows the variation of SAR values for $\mathrm{Co}_{x} \mathrm{Fe}_{3-\mathrm{x}} \mathrm{O}_{4}$ nanoparticles of size $12 \mathrm{~nm}$. The obtained SAR value of pure $\mathrm{Fe}_{3} \mathrm{O}_{4}$ nanoparticles is $132 \mathrm{~W} / \mathrm{g}$ at $265 \mathrm{kHz}$ with an ACMF amplitude of 491 Oe and after being doped with $\mathrm{Co}^{2+}$ ions, the heating efficiency is greatly improved to $534 \mathrm{~W} / \mathrm{g}$. Besides, with the increase of the ACMF amplitude from 184 to $491 \mathrm{Oe}$, the SAR values of $\mathrm{Fe}_{3} \mathrm{O}_{4}$ and $\mathrm{Co}_{0.5} \mathrm{Fe}_{2.5} \mathrm{O}_{4}$ nanoparticles increase from 81 to $132 \mathrm{~W} / \mathrm{g}$ and 220 to $534 \mathrm{~W} / \mathrm{g}$, respectively. As discussed above, the substitution of Co ions leads to an increase in $H_{C}$ at the cost of lower saturation magnetization. However, as nanoparticles with high $H_{C}$ and moderate $M_{S}$ are found to be the best heating agents, the modification of the composition proved to be effective in maximizing the SAR. As can be seen in Figure 10B-D, the SAR values are related to the hysteresis loop area. When the applied field keeps increasing, the $H_{C}$ and hysteresis loop area rapidly increase and strongly enhance the SAR value. It is important to note that, the Co-doped $\mathrm{Fe}_{3} \mathrm{O}_{4} \mathrm{NPs}$ exhibit better heating activity compared to the pristine $\mathrm{Fe}_{3} \mathrm{O}_{4}$ and $\mathrm{CoFe}_{2} \mathrm{O}_{4} \mathrm{NPs}$ prepared by a similar approach [97]. The effect of composition on the hyperthermia heating properties will be further discussed in the Section 3.4. 
(A)

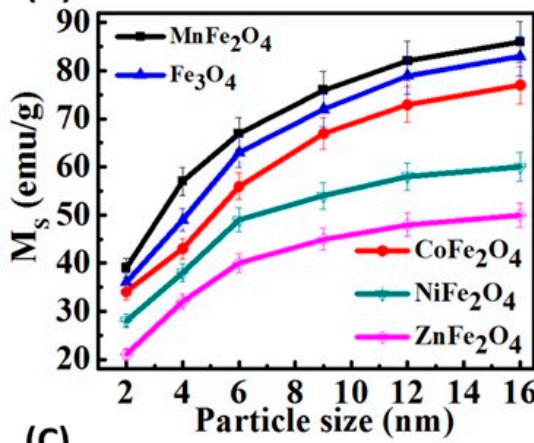

(C)

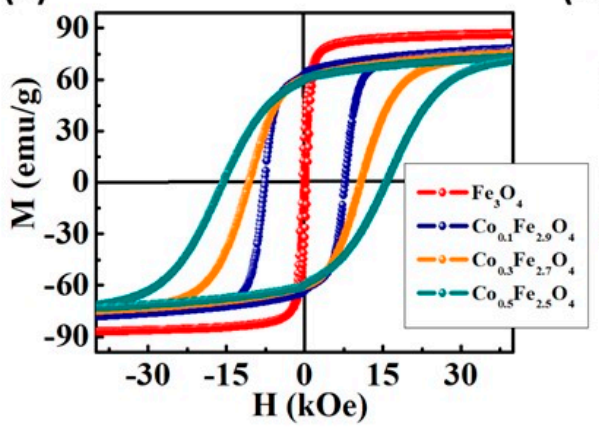

(B)
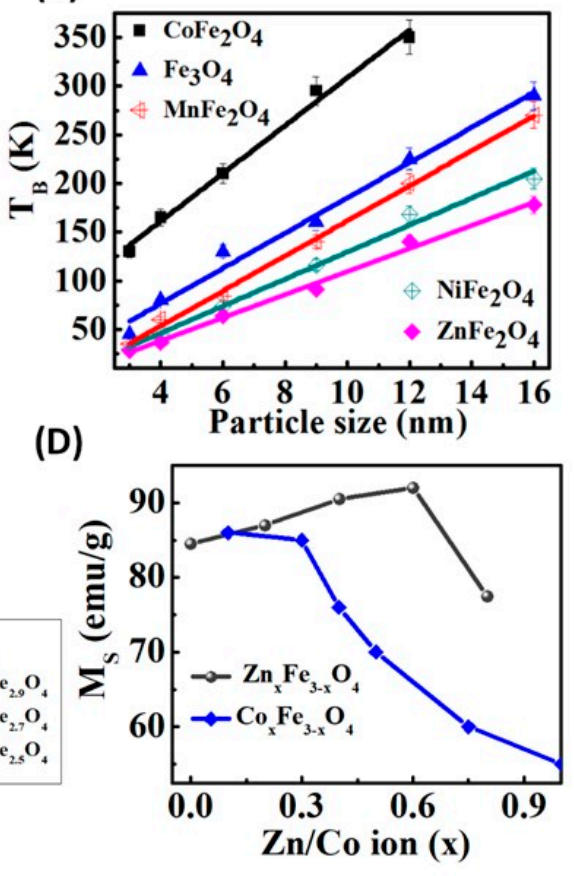

Figure 9. (A) Saturation magnetization vs. NPs size plot for $\mathrm{MFe}_{2} \mathrm{O}_{4}$ NPs demonstrates the sharp increase of magnetization value with respect to NPs size [92]. (B) Blocking temperature vs. NPs size plot indicates a linear relationship between blocking temperature and NPs size [92]. (C) Hysteresis curves of $\mathrm{Co}_{x} \mathrm{Fe}_{3-x} \mathrm{O}_{4}$ nanoparticles with $x=0,0.1,0.3$ and 0.5 at $10 \mathrm{~K}$ [100]. (D) Dependences of $M_{S}$ on the $\mathrm{Zn}$ and $\mathrm{Co}$ substitution content $(x)$ in $\mathrm{Fe}_{3} \mathrm{O}_{4}$ nanoparticles [99,102].
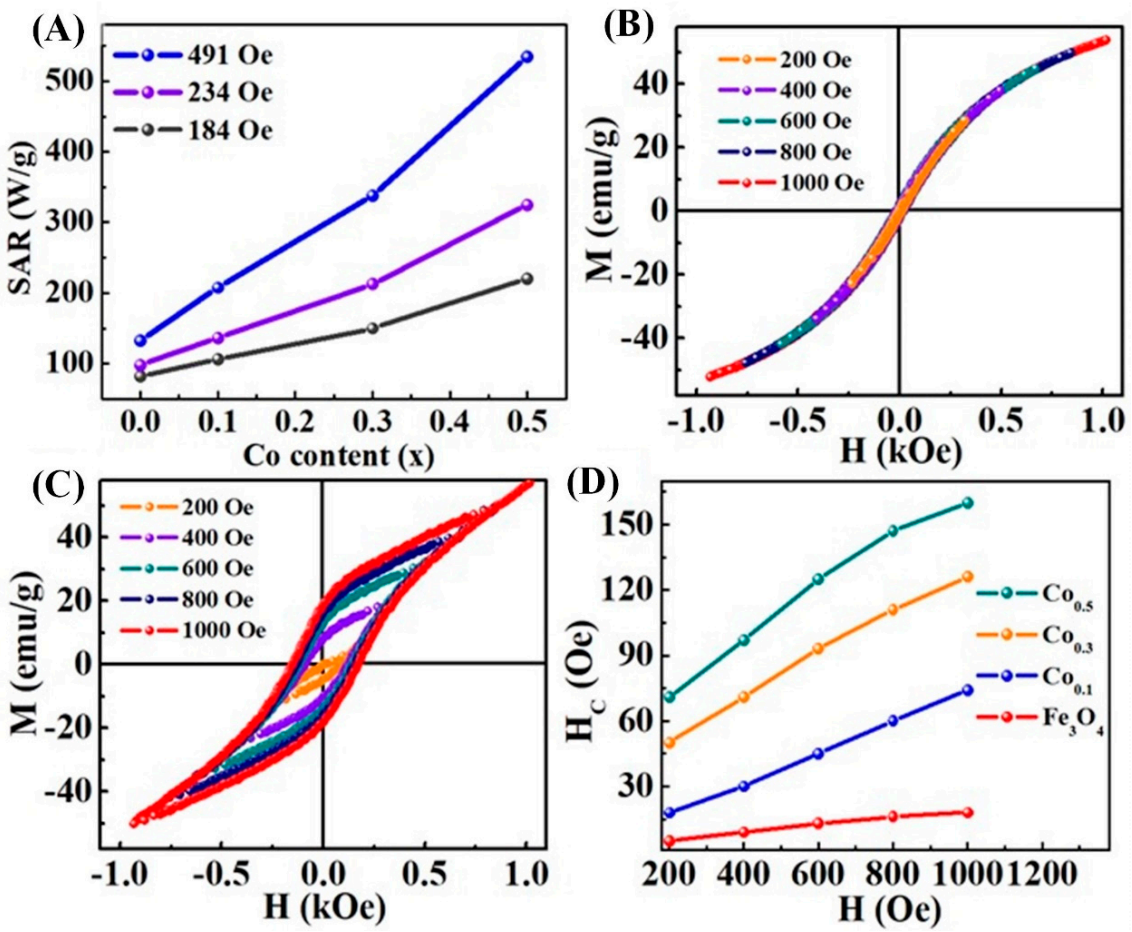

Figure 10. (A) Shows a plot of SAR as a function of Co content in $\mathrm{Fe}_{3} \mathrm{O}_{4} \mathrm{NPs}$ across several values of applied ACMF field (184-491 Oe). (B,C) Show the room temperature minor $\mathrm{M}(\mathrm{H})$ loops at maximum magnetic field of 200, 400, 600, 800 and 1000 Oe for $\mathrm{Fe}_{3} \mathrm{O}_{4}$ and $\mathrm{Co}_{0.5} \mathrm{Fe}_{2.5} \mathrm{O}_{4}$ nanoparticles, respectively. (D) Shows the coercive field as a function of Co content in $\mathrm{Fe}_{3} \mathrm{O}_{4}$ NPs at various applied magnetic fields [100]. 


\subsection{Shape Effects}

Shape anisotropy is an extrinsic energy that comes from an induced demagnetizing field ( $H_{d}=-N_{d} M_{S}$, where $N_{d}$ is the demagnetizing factor determined by the shape) of a magnetized body. In the case of spherical morphology, the surface poles are distributed over the surface such that there are none at the equator and most are at the poles. Hence the demagnetizing field is $H_{d}=-1 / 3 M_{S}$ and $N_{d}=1 / 3$ (for sphere). While, in the case of anisotropic morphology, the distribution of surface poles depends on the direction of magnetization. For example, in a prolate ellipsoid that is magnetized parallel to the major axis $c$, the free poles are farther apart, hence, $N_{c}<1 / 3$ (as $H_{d} \propto 1 / r^{2}$ ). Similarly, if it is magnetized along axis $a$, the free poles are close to each other, hence, $N_{a}>1 / 3$. The general expression of shape anisotropy constant $\left(K_{s h}\right)$ is $K_{s h}=M_{S}{ }^{2}\left(N_{a}-N_{c}\right) / 2[35,103]$. A predominant effect of shape anisotropy on stoichiometry, coercivity and $M_{S}$ values has been observed in different anisotropic magnetic nanostructures [104-110].

Recently, $\mathrm{Fe}_{3} \mathrm{O}_{4}$ nanowires were synthesized via high-temperature reduction of $\alpha$-FeOOH NWs in a fluidized bed reactor [111]. The removal of water molecules and the shearing of the oxide ion planes from $\mathrm{AB}$ to $\mathrm{ABC}$ stacking during phase transformation from the $\mathrm{FeOOH}$ to $\mathrm{Fe}_{3} \mathrm{O}_{4}$ make these $\mathrm{Fe}_{3} \mathrm{O}_{4}$ NWs porous (Figure 11A,B) [112]. The magnetization curves for $\mathrm{Fe}_{3} \mathrm{O}_{4}$ parallel to aligned NWs exhibited a $M_{R}$ of $0.51 M_{S}$ and $H_{C}$ of 583 Oe, respectively. When the samples were measured perpendicular to the alignment direction, remanence of $M_{R}=0.30 M_{S}$ was obtained, which indicates the influence of shape anisotropy $[113,114]$. A prominent effect of the MNPs shape on the surface anisotropy has also been observed in anisotropic-shaped nanoparticles. For example, the Verwey transition in $\mathrm{Fe}_{3} \mathrm{O}_{4}$ is a structural phase transition that is observed in the smallest octahedral NPs $(6 \mathrm{~nm})$ but does not even occur in the bigger size spherical NPs $(13 \mathrm{~nm}$ ) (Figure 12B,C) [68]. While the spherical-shape NPs shows the predictable superparamagnetic blocking behavior, which indicates the role of shape anisotropy on the stoichiometry. It is found that the facets of octahedral particles are consist of the most energetically stable [111] planes and the facets are protected against surface oxidation due to oleylamine coating. Thus, the surface anisotropy is significantly reduced, since the flat surface of the octahedron has fewer broken bonds and oxygen vacancies. A lower concentration of defects and almost no oxidized layer at the surface afford a better stoichiometry to the octahedral shape NPs and make the appearance of Verwey transition. In contrast, spherical NPs have highly disordered spins distributed across its outer surface which contribute to poor stoichiometry. As the Verwey transition is highly sensitive to stoichiometry, it is suppressed by the superparamagnetic blocking behavior.

The effect of shape anisotropy on ordering of surface atomic spins has also been well demonstrated by Cheon et al. [2]. Among a cube and a sphere with the same material volume and number of cations of $\mathrm{Zn}_{0.4} \mathrm{Fe}_{2.6} \mathrm{O}_{4}$ nanoparticles, the cube has greater $M_{S}\left(165 \mathrm{emu} / \mathrm{g}_{(\mathrm{Fe}+\mathrm{Zn})}\right)$ compared to that of the sphere $\left(145 \mathrm{emu} / \mathrm{g}_{(\mathrm{Fe}+\mathrm{Zn})}\right)($ Figure 12D). The cube has lower energy surface facets of family (100); in contrast, the surface of a spherical nanoparticle is constructed of different facets, which results in a larger surface spin disorder, hence higher surface anisotropy. A simulated result shows that the density of the disordered spins is higher in the sphere than in the cube (Figure 12E,F). The images are color-mapped according to the angle of the spin deviation versus the external magnetic field, red indicates ordered spins and blue indicates highly disordered spins. The disordered spins in blue are dominant at the corners of the cube, while they are broadly distributed at the surface of the sphere. The shape effect has also been noticed in $\mathrm{Fe}_{3} \mathrm{O}_{4}$ nanostructures of different shapes. The change in magnetization value with respect to shape and size of these nanostructures is summarized in Figure 12G. Among all these magnetic nanostructures, cube and octahedron exhibit enhanced $M_{S}$ values. The enhanced $M_{S}$ values are assumed to be due to anisotropic shape which lowers the surface spin disordered effect as explained in $\mathrm{Zn}_{0.4} \mathrm{Fe}_{2.6} \mathrm{O}_{4}$ nanocubes case $[2,68]$. The $M_{S}$ value of the rods is $50-65 \mathrm{emu} / \mathrm{g}$. The low $M_{S}$ value is attributed to the surface spin canting or surface organic defective layer of the nanorods. 
(A)
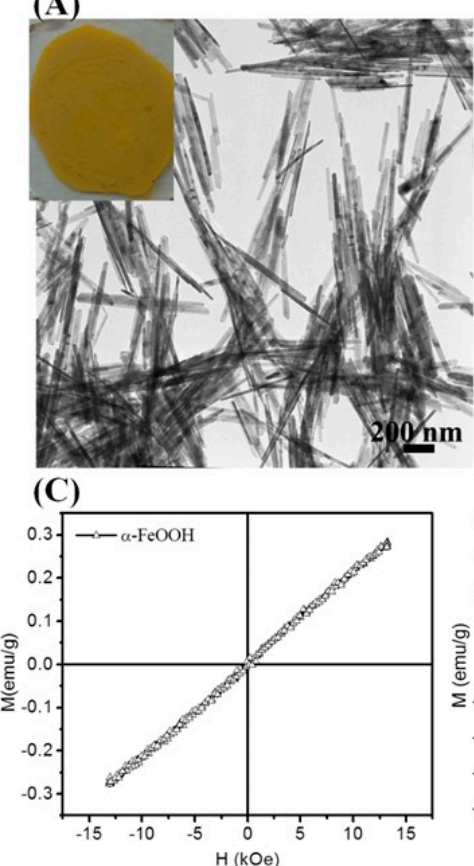

(B)
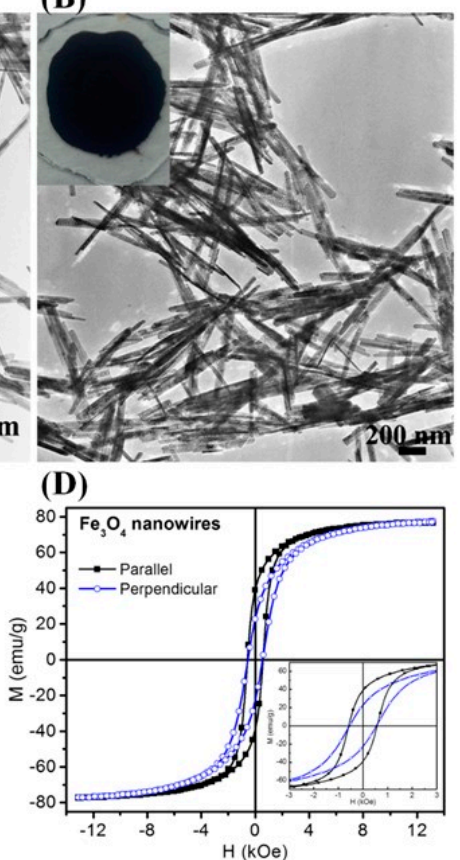

Figure 11. (A) TEM image of $\alpha$-FeOOH NWs synthesized by hydrolysis of $\mathrm{FeCl}_{3}$ at $160{ }^{\circ} \mathrm{C}$. Inset shows the $\alpha$-FeOOH NWs powder produced by a single experiment. (B) TEM image of $\mathrm{Fe}_{3} \mathrm{O}_{4} \mathrm{NWs}$ synthesized by annealing $\alpha$-FeOOH NWs at $300{ }^{\circ} \mathrm{C}$. Inset shows the color of $\mathrm{Fe}_{3} \mathrm{O}_{4} \mathrm{NW}$ powder obtained after annealing $\alpha$-FeOOH NWs. Room temperature hysteresis loops of (C) $\alpha$-FeOOH NWs and (D) $\mathrm{Fe}_{3} \mathrm{O}_{4}$ NWs. The insert of D shows the low-field magnetization loops [111].

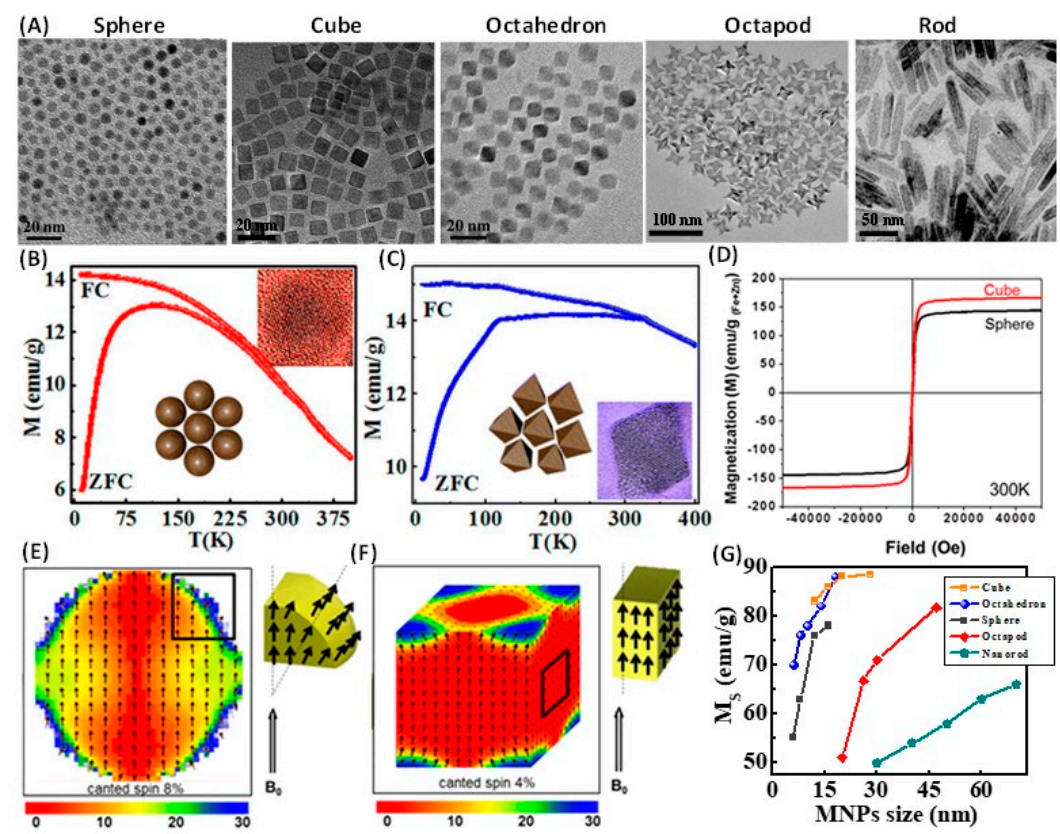

Figure 12. (A) TEM images of $\mathrm{Fe}_{3} \mathrm{O}_{4}$ spheres ( $8 \mathrm{~nm}$ ), cubes (12 nm) [115], octahedrons (10 nm) [68], octopods [116] and rods [69] are obtained through thermolysis of iron salt. FC and ZFC magnetization curves of (B) spherical and (C) octahedral $\mathrm{Fe}_{3} \mathrm{O}_{4}$ nanoparticles at the applied field of 200 Oe [68]. (D) Room temperature M-H curves of cube and sphere-shaped $\mathrm{Fe}_{3} \mathrm{O}_{4}$ nanoparticles [2]. Simulated magnetic spin structures of (E) cube and (F) sphere. The color map indicates the degree of spin disorder in an external magnetic field, where red indicates ordered spins and blue indicates disorder spins. The right corners of parts $\mathrm{E}$ and $\mathrm{F}$ show their local surface spin arrangements [2]. (G) The variation of $M_{S}$ of different anisotropic $\mathrm{Fe}_{3} \mathrm{O}_{4}$ with increase of size $[68,69,117]$. 
From the above discussion, we have seen that magnetic properties, particularly the $M_{S}$ and magnetic anisotropy strongly varied with the shape of the MNPs. Based on the superior magnetic properties, these anisotropic nanoparticles have also been shown to be a better heating candidate compared to the spherical counterpart. Recently, a large improvement in SAR has been reported for cubes, octopods, octahedrons, plates and rods, as a result of their improved magnetic anisotropy. Taking into account the proven advantages of high-aspect-ratio $\mathrm{Fe}_{3} \mathrm{O}_{4}$ nanowires/nanorods over their spherical and cubic counterparts, such as larger surface area, enhanced blood circulation time, and prolonged retention in tumors, Das et al. demonstrated higher heating activity in $\mathrm{Fe}_{3} \mathrm{O}_{4}$ nanorods of aspect ratio from 6 to 11 [89]. Figure 13A shows a comparison between spherical and cubic NPs and compared their SAR values with those of the $\mathrm{Fe}_{3} \mathrm{O}_{4}$ nanorods. Interestingly, the nanorods have higher SAR values than those obtained for the sphere and cube-shaped NPs, particularly in the high field region ( $>600 \mathrm{Oe}$ ). At 800 Oe the SAR value is $862 \mathrm{~W} / \mathrm{g}$ for the nanorod, while it is only about 140 and $314 \mathrm{~W} / \mathrm{g}$ for the spheres and cubes, respectively. The nanorods exhibit superior heating efficiency because of their larger $K_{\text {eff }}$ values, related with their shape anisotropy. Further, increasing the aspect ratio of the nanorods from 6 to 11 improves the SAR by 1.5 times.

(A)

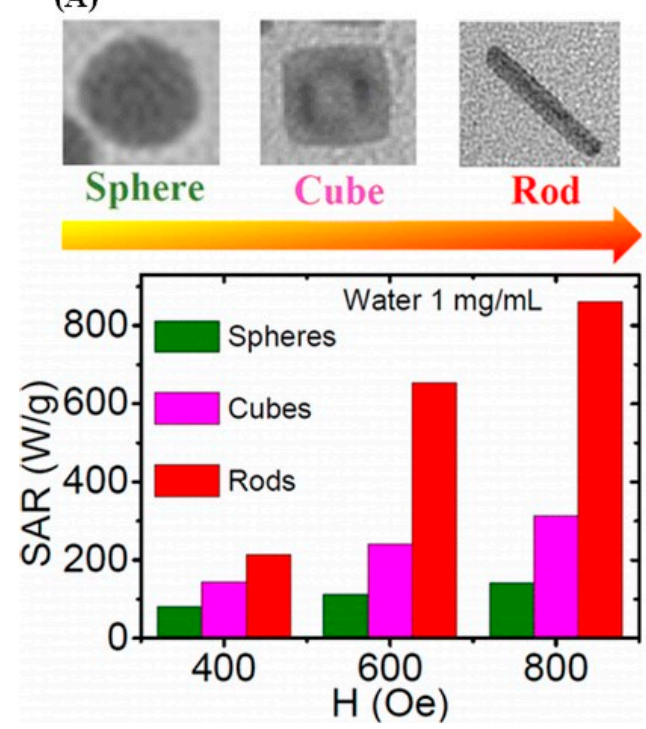

(B)

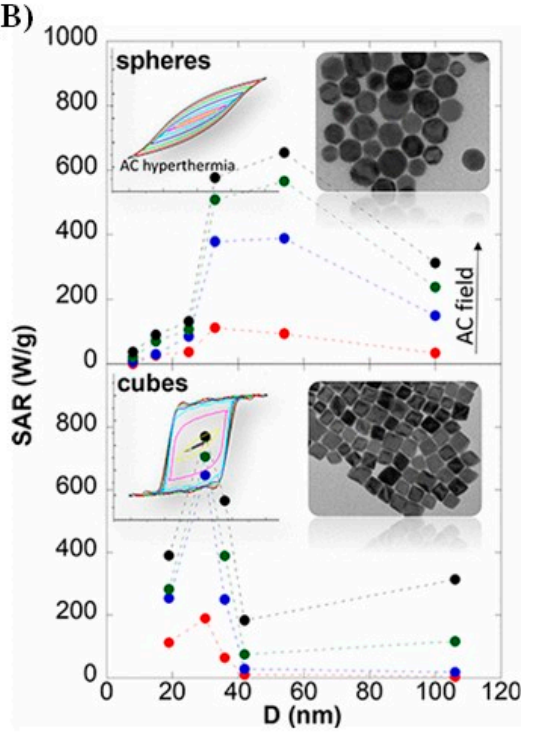

Figure 13. (A) SAR vs. field plot for the $\mathrm{Fe}_{3} \mathrm{O}_{4}$ spheres, cubes, and nanorods of nearly the same volume $\left(\sim 2000 \mathrm{~nm}^{3}\right)$ [89]. (B) SAR vs. size curves for the sphere and cube-shaped NPs measured in water $(1 \mathrm{mg} / \mathrm{mL})$ under AC magnetic fields of $0-800$ Oe and at frequency of $300 \mathrm{kHz}$ [118].

From the above discussion we have already seen a higher heating activity for cubes than the spheres. For further understanding, Nemati et al. demonstrated a comparison between sphere and cube-shaped nanoparticles in a wide range of sizes, $\sim 10-100 \mathrm{~nm}$ (Figure 13B) [118]. The spheres show negligible SAR for sizes less than $13 \mathrm{~nm}$, but then sharply increases beginning near $26 \mathrm{~nm}$ until it reaches a broad maximum of $\sim 650 \mathrm{~W} / \mathrm{g}$ at 800 Oe around $52 \mathrm{~nm}$. The very low SAR values observed by the small-sized nanospheres is related to their broader size distribution. However, for the cube-shaped NPs, the heating efficiency shows a very different trend; the size evolution of the SAR surprisingly increases at $30 \mathrm{~nm}$ up to $\sim 800 \mathrm{~W} / \mathrm{g}$ at 800 Oe and then decays immediately with increasing size, reaching a minimum for the $42 \mathrm{~nm}$ cubes.

\subsection{Optimization of Intraparticle and Interparticle Interactions}

\subsubsection{Effect of Interparticle Interactions}

It is known that in concentrated particle systems the magnetic behavior of the particles is significantly influenced by interparticle interactions. The magnetic properties of such MNP systems 
are studied using a frozen state of ferrofluid where MNPs are dispersed in solvent or by embedding the MNPs in a solid matrix [43,119-121]. Multiple studies report that the anisotropic-energy barrier in interacting nanoparticle systems increases with the increase of interparticle interaction, i.e., by decreasing the separation distance among the MNPs. Thus, the blocking temperature of strongly interacting MNP systems is higher than that in the corresponding isolated MNP system [122-124]. For example, $\mathrm{Fe}_{3} \mathrm{O}_{4} / \mathrm{SiO}_{2}$ core-shell nanoparticles with different shell thicknesses (Figure 14A-C) are prepared to understand the effect of interparticle interactions on the magnetic properties [125-127]. As the shell thickness decreases, the influence of interparticle dipolar interaction becomes apparent and quasi-magnetostatic states like superspin-glass (SSG) and super-ferromagnetic are observed. Figure $14 \mathrm{D}$ shows the temperature-dependent magnetization of $\mathrm{Fe}_{3} \mathrm{O}_{4} / \mathrm{SiO}_{2}$ core-shell nanoparticles. With increasing the $\mathrm{SiO}_{2}$-shell thickness on the MNPs, the $T_{B}$ is lowered and the field-cooled magnetization $\left(M_{F C}\right)$ at low temperature becomes pronounced. These features are particularly observed in conventional superparamagnetic NPs systems in which the interparticle interaction is negligible. In the most concentrated sample, L12, the $M_{F C}$ at low-temperature displays no increase but rather a slight decrease, which is a superspin-glass like behavior. The flat nature of $M_{F C}$ curves can be more prominent in dense nanoparticle assemblies. This cooperative magnetic behavior can also be described from the field dependence of $M_{Z F C}$ and $M_{F C}$ measurements. When the applied magnetic field increases, the superspin glass transition peak is prominent and changes to a plateau like shape as observed in $4 \mathrm{~nm} \mathrm{Fe}_{3} \mathrm{O}_{4}$ nanoparticle assemblies (Figure 14E). Further, the temperature at which the irreversibility between $M_{Z F C}$ and $M_{F C}$ curves appears shifts towards lower values with the increases in magnetic field (5-500 Oe), a characteristic of spin-glass systems.

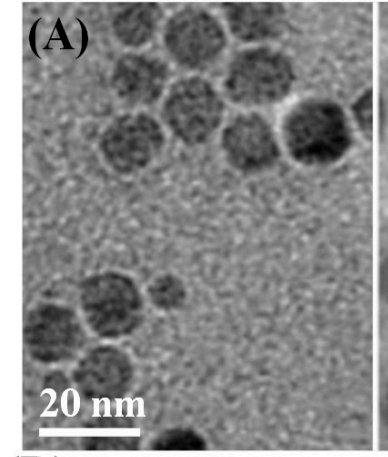

(D)

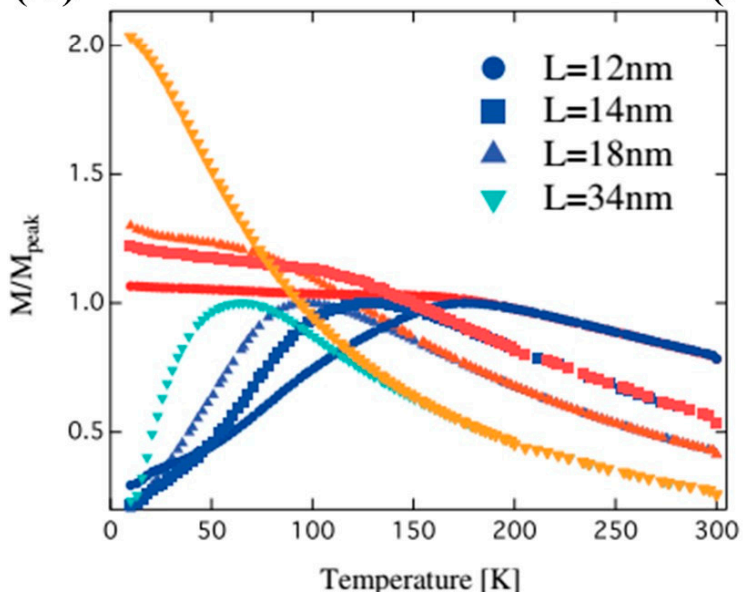

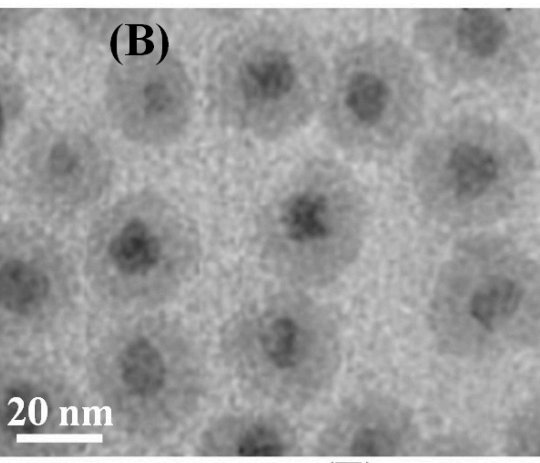

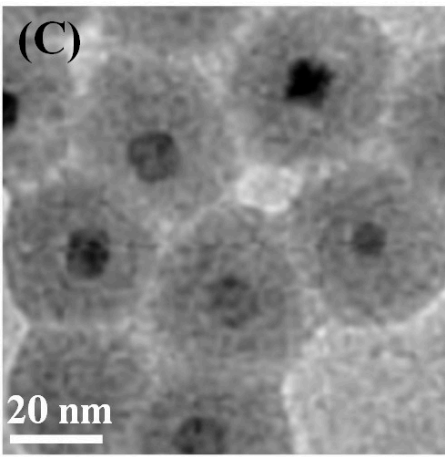

(E)

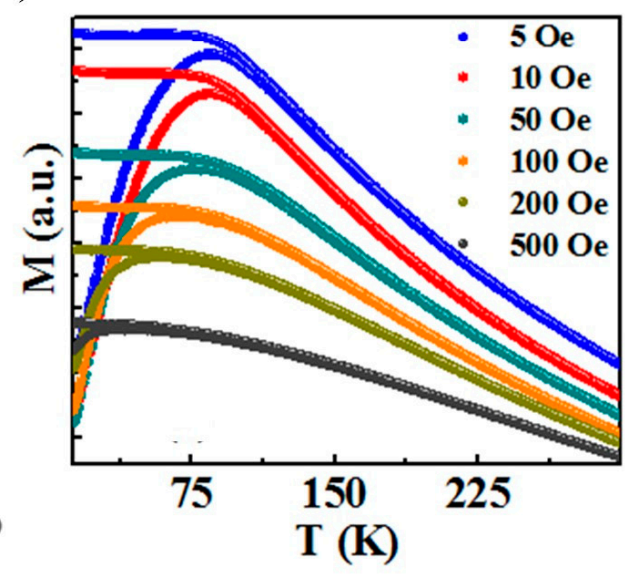

Figure 14. (A-C) TEM images of $\gamma-\mathrm{Fe}_{2} \mathrm{O}_{3} \mathrm{NPs}$ (average diameter $=11 \mathrm{~nm}$ ), $\gamma-\mathrm{Fe}_{2} \mathrm{O}_{3} / \mathrm{SiO}_{2} \mathrm{NPs}$ with $\mathrm{SiO}_{2}$ layer thickness, $\mathrm{L}=26 \mathrm{~nm}$, and $34 \mathrm{~nm}$, respectively. (D) Temperature-dependent magnetization of the $\gamma-\mathrm{Fe}_{2} \mathrm{O}_{3} / \mathrm{SiO}_{2} \mathrm{NPs}$ with $\mathrm{SiO}_{2}$ layer thickness, $\mathrm{L}=12,14,18$, and $34 \mathrm{~nm}$ under $\mathrm{ZFC}$ and FC conditions [125]. (E) The ZFC and FC magnetization are measured at the indicated field values for $4 \mathrm{~nm} \mathrm{Fe}_{3} \mathrm{O}_{4}$ nanoparticles [43]. 
The inter-particle interaction can become more pronounced in the case of nanoparticle assemblies, superlattices or aggregates. In fact, these secondary nanostructures (magnetic nanoparticle nano-assemblies, noted MNPAs), the dipolar coupling and exchange-coupling (Figure 15A) between the neighboring nanocrystals can be comparable to the magnetic anisotropy energy. Therefore, the energy barrier of individual nanoparticles is strongly impacted by exchange and dipolar interactions [70]. The increase in the energy of the barrier shifts the superparamagnetic blocking temperature of MNPAs to a higher temperature than that of the isolated nanoparticles. Moreover, the MNPAs also exhibits a phase transition, from a superparamagnetic state to a collective magnetic behavior at low temperature. The quasi-magnetostatics state is caused by the frustration of interparticle interactions that are induced due to randomness in nanoparticle positions and anisotropy-axes orientations. The collective behavior is called superspin-glass and has been recently observed in $\mathrm{Fe}_{3} \mathrm{O}_{4}, \gamma-\mathrm{Fe}_{2} \mathrm{O}_{3}$ and $\mathrm{CoFe}_{2} \mathrm{O}_{4}$ nanoparticle nano-assemblies $[7,8,128]$. For example, Lartigue $e t$ al. synthesized different sized nanoparticle assemblies $(19.7,22.2,24.0$, and $28.8 \mathrm{~nm})$ of $\gamma-\mathrm{Fe}_{2} \mathrm{O}_{3}$ nanoparticles $(10 \mathrm{~nm})$ using a single-step high-temperature hydrolysis approach (Figure 15B,C) [24,25]. These MNPAs present a bulk-like $M_{S}$ value ( $80 \mathrm{emu} / \mathrm{g}$ for maghemite), while the $10 \mathrm{~nm}$ nanoparticles show a $30 \%$ reduction of $M_{S}$ value with respect to the bulk value (Figure 15E). The susceptibility of the MNPAs is higher than that of the $10 \mathrm{~nm}$ nanoparticles and increases with the increase in the sizes of the MNPAs. The higher $M_{S}$ values in the case of the MNPAs is believed to be due to the existence of exchange interactions between the surface atoms of neighboring nanoparticles. The exchange-coupling between closely packed nanoparticles with different orientations of easy axes can certainly result in a rotation of the spin structure to an aligned ordered structure at the interface as shown in Figure 15A. The collective behavior of spins at the interface lowers the surface anisotropy and also results in high magnetic susceptibility (Figure 15D). Further, in comparison to nanoparticles, a large increase in the blocking temperature by $150 \mathrm{~K}$ is observed for MNPAs (Figure 15D). In addition, as expected the FC curve flattens out below $T_{B}$. The $M_{F C}$ remains flat below $T_{B}$, indicating the presence of a spin-glass-like state due to magnetic interactions among the nanoparticles within the assembled structure [8].
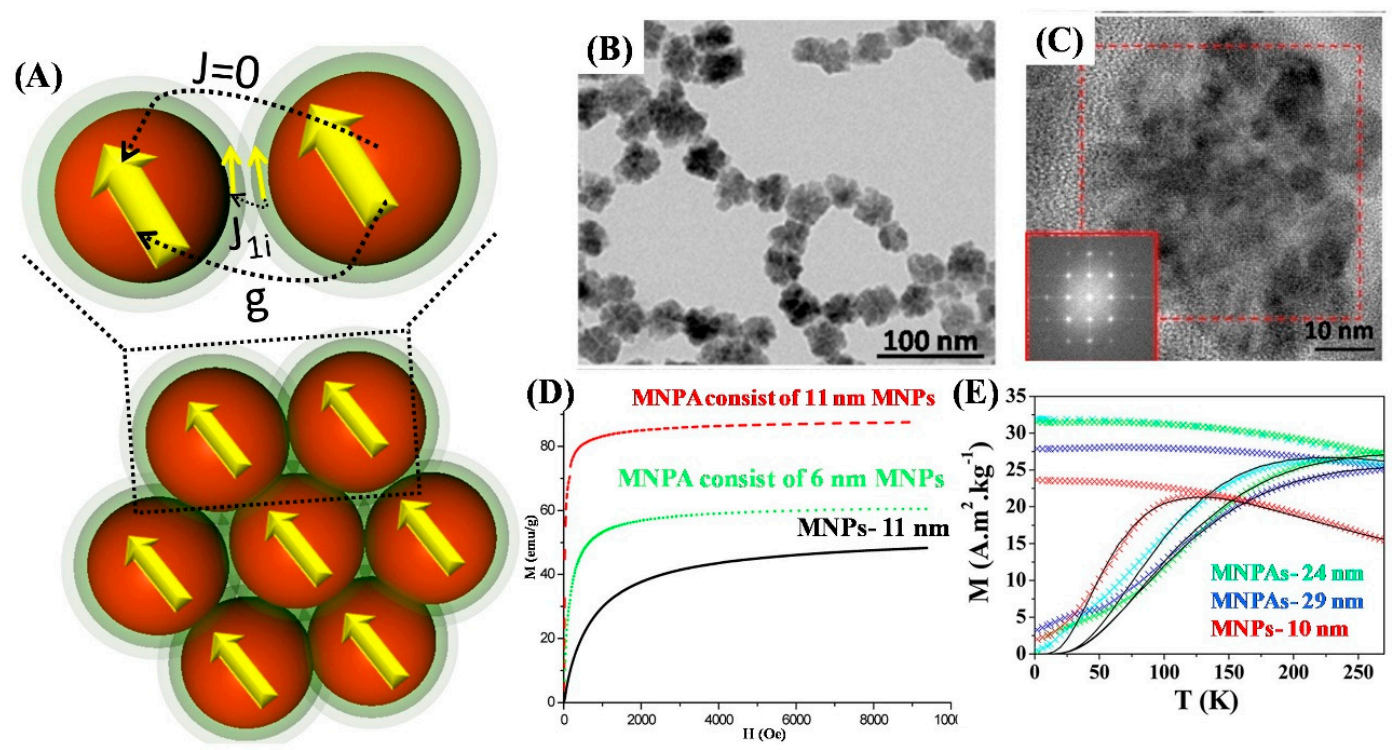

Figure 15. (A) Schematic illustration of the supermoment structure and the intra-particle as well as inter-particle interactions in a nanoparticle assembly. Outermost light green color: Surfactant polymeric layer [70]. (B) TEM and (C) HR-TEM micrographs and Fourier transformation of flowerlike nanoparticles [24]. (D) Magnetization curves of $11 \mathrm{~nm}$-sized nanoparticles synthesized via coprecipitation (green dotted line), $6 \mathrm{~nm}$ nanoparticles synthesized in diethylene glycol (black solid line) and $11 \mathrm{~nm}$ nanoparticle assemblies synthesized in a mixture of diethylene glycol and $N$-methyl diethanolamine (red dashed line). (E) ZFC-FC magnetization curves taken with an applied field of 50 Oe: $24 \mathrm{~nm}$ (cyan), $29 \mathrm{~nm}$ (blue)-sized nanoparticles assembly and $10 \mathrm{~nm}$ (red)-sized nanoparticles [25]. 
Recently, the MNPAs, also named nanoflowers, nanocluster, and nanocrystal assemblies have shown good heating efficiency due to cooperative magnetism among nanocrystals within the multi-domain nanostructure. Lartigue et al. demonstrated a comparison of heating performance of MNPAs (multi-core nanostructures) with the single-core nanoparticles [25]. Under field conditions of $29 \mathrm{kA} / \mathrm{m}$ and $520 \mathrm{kHz}$, the temperature increased at a rate of $1.04{ }^{\circ} \mathrm{C} / \mathrm{s}$ for MNPAs, while that for single-core nanoparticles showed only $0.15^{\circ} \mathrm{C} / \mathrm{s}$ (Figure 16A). Compared to the rest of the size-sorted multi-core nanostructures, the largest sized sample showed the highest SAR (Figure 16B). More importantly, the SAR of the multi-core nanoparticles is much higher than that reported for single-core nanoparticles. In fact, they are among the best heating materials reported so far for iron oxide nanoparticles. A similar trend is also observed in $\mathrm{MFe}_{2} \mathrm{O}_{4}(\mathrm{M}=\mathrm{Mn}, \mathrm{Fe}, \mathrm{Co}$ and Ni) nanoparticle nanoassemblies produced via thermal decomposition of metal chloride in ethylene glycol in the presence of ethylenediamine. The heating performance of the $\mathrm{MFe}_{2} \mathrm{O}_{4} \mathrm{MNPAs}$ as a function of nanoassemblies and nanocrystals size are measured at a frequency of $247 \mathrm{kHz}$ and ACMF amplitude of 310 Oe. The SAR values of all the $\mathrm{MFe}_{2} \mathrm{O}_{4}$ MNPAs display an increase trend with the increase in size of MNPAs while keeping the nanocrystal size same (Figure 16C). The results from the magnetic characterization verify the enhancement of $M_{S}$ value with the increase of MNPAs size and the presence of collective magnetic dynamics, i.e., the collective Néel relaxation of nanocrystals within the assembly. Thus, the increase of SAR with MNPAs size is ascribed to the cooperative Néel relaxation and the high particle magnetic moment. An important composition effect has also been noticed in $\mathrm{MFe}_{2} \mathrm{O}_{4} \mathrm{MNPAs}$. In contrast to $\mathrm{CoFe}_{2} \mathrm{O}_{4}$ (high $\mathrm{K}_{\text {eff }}$ ) and $\mathrm{MnFe}_{2} \mathrm{O}_{4}$ (high $\mathrm{M}_{S}$ ), the $\mathrm{Fe}_{3} \mathrm{O}_{4}$ MNPAs have an exclusively high SAR value in all the size ranges (Figure 16D). From the Section 2, we know that high $K_{\text {eff }}$ leads to a shift in the critical particle size associated with the maximum heating to a lower particle size value (as critical radius ' $R_{0}{ }^{\prime}$ corresponding to maximum heating $R_{0} \propto 1 / K_{e f f}$ ). In this case, the calculated critical nanocrystal size corresponding to maximum SAR are 6, 15 and $27 \mathrm{~nm}$ for $\mathrm{CoFe}_{2} \mathrm{O}_{4}, \mathrm{Fe}_{3} \mathrm{O}_{4}$ and $\mathrm{MnFe}_{2} \mathrm{O}_{4}$ nanocrystals, respectively. Thus, the $\mathrm{MnFe}_{2} \mathrm{O}_{4}$ and $\mathrm{Fe}_{3} \mathrm{O}_{4}$ MNPAs exhibit a maximum heating at the nanocrystalline size of $14 \mathrm{~nm}$, i.e., $80 \mathrm{~nm}$ sized MNPAs while $\mathrm{CoFe}_{2} \mathrm{O}_{4} \mathrm{MNPAs}_{\text {displays }}$ the maximum heating activity for $4 \mathrm{~nm}$ size nanocrystals, i.e., $50 \mathrm{~nm}$ sized MNPAs.
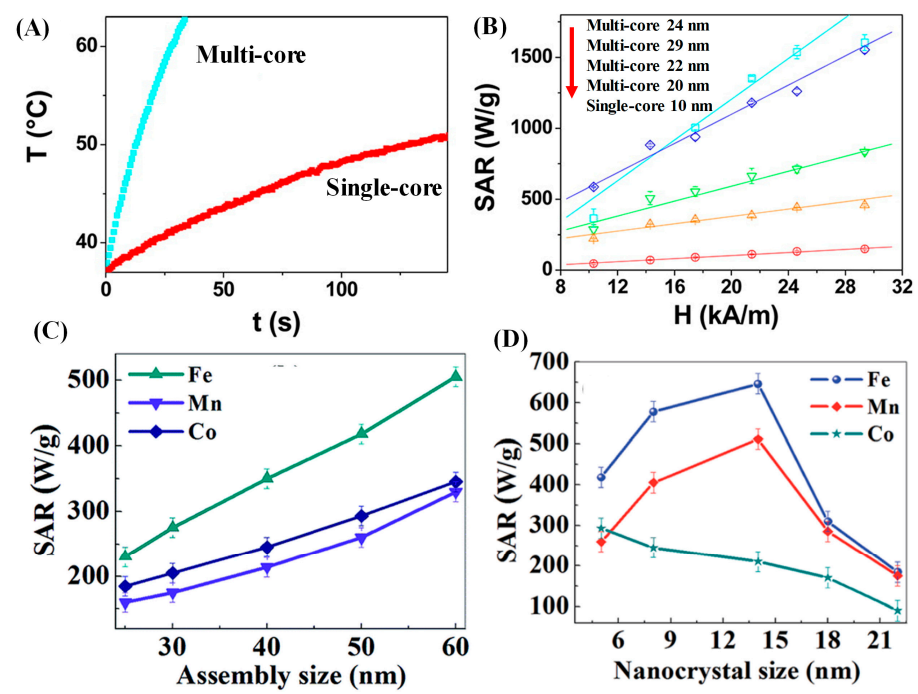

Figure 16. A comprehensive demonstration of the optimization of hyperthermia heating efficiency of $\mathrm{MFe}_{2} \mathrm{O}_{4}$ MNPAs by controlling size, composition, and magnetic coupling among the nanocrystals within the nanoassembly. (A) Heating curves for multi-core and single-core $\mathrm{Fe}_{3} \mathrm{O}_{4}$ nanostructures are recorded under an ACMF of amplitude $29 \mathrm{kA} / \mathrm{m}$ and at frequency $520 \mathrm{kHz}$ [25]. (B) SAR values as a function of the ACMF amplitude at frequency $f=520 \mathrm{kHz}$ for multi-core $24 \mathrm{~nm}$ (cyan), multi-core $29 \mathrm{~nm}$ (blue), multi-core $22 \mathrm{~nm}$ (green), multi-core $20 \mathrm{~nm}$ (orange), and single-core $10 \mathrm{~nm}$ (red) [25]. (C) The SAR as a function of nanoassembly size of $\mathrm{MFe}_{2} \mathrm{O}_{4}(\mathrm{M}=\mathrm{Mn}, \mathrm{Fe}$ and Co) with nanocrystal size $4 \mathrm{~nm}$ [70]. (D) The SAR as a function of nanoassembly size of $\mathrm{MFe}_{2} \mathrm{O}_{4}$ with variation of nanocrystal size from 6 to $21 \mathrm{~nm}$ [70]. 
In order to demonstrate the efficacy of magnetic nanoparticles solution for cancer treatment, the hyperthermia heating properties of magnetic nanoparticles are measured in the cellular environment. The study demonstrated that irrespective of size, shape, and compositions of the magnetic nanoparticles, the heating activity rapidly dropped following the internalization [129]. More importantly, the SAR values in the cellular environments are half than those obtained in the solution. The low SAR values are related to the cellular confinement effect, which completely inhibited the Brownian relaxation. In contrast to the superparamagnetic nanoparticles, the heating properties of ferromagnetic nanoparticles are significantly impacted after contact with cells. Despite the above issues, several research works have demonstrated that the nanoparticles morphology, magnetic and chemical property modification can address the above challenges [130-133].

\subsubsection{Effects of Intraparticle Interactions}

Exchange coupled core-shell nanoparticles with soft core (low anisotropy, high magnetization) and hard shell (high anisotropy) or vice versa is a prominent example of an intraparticle interacting system. The core-shell nanoparticles exhibit improved magnetic properties, but more importantly they produce an intermediate magnetic anisotropy and saturation magnetization compared to both the constituents (Figure 17A) [124-138]. In the nanocomposite system, the magnetization of the soft magnetic phase is able to rotate coherently with that of the hard-magnetic phase, thus allowing us to utilize the advantages of soft and hard magnetic phases.
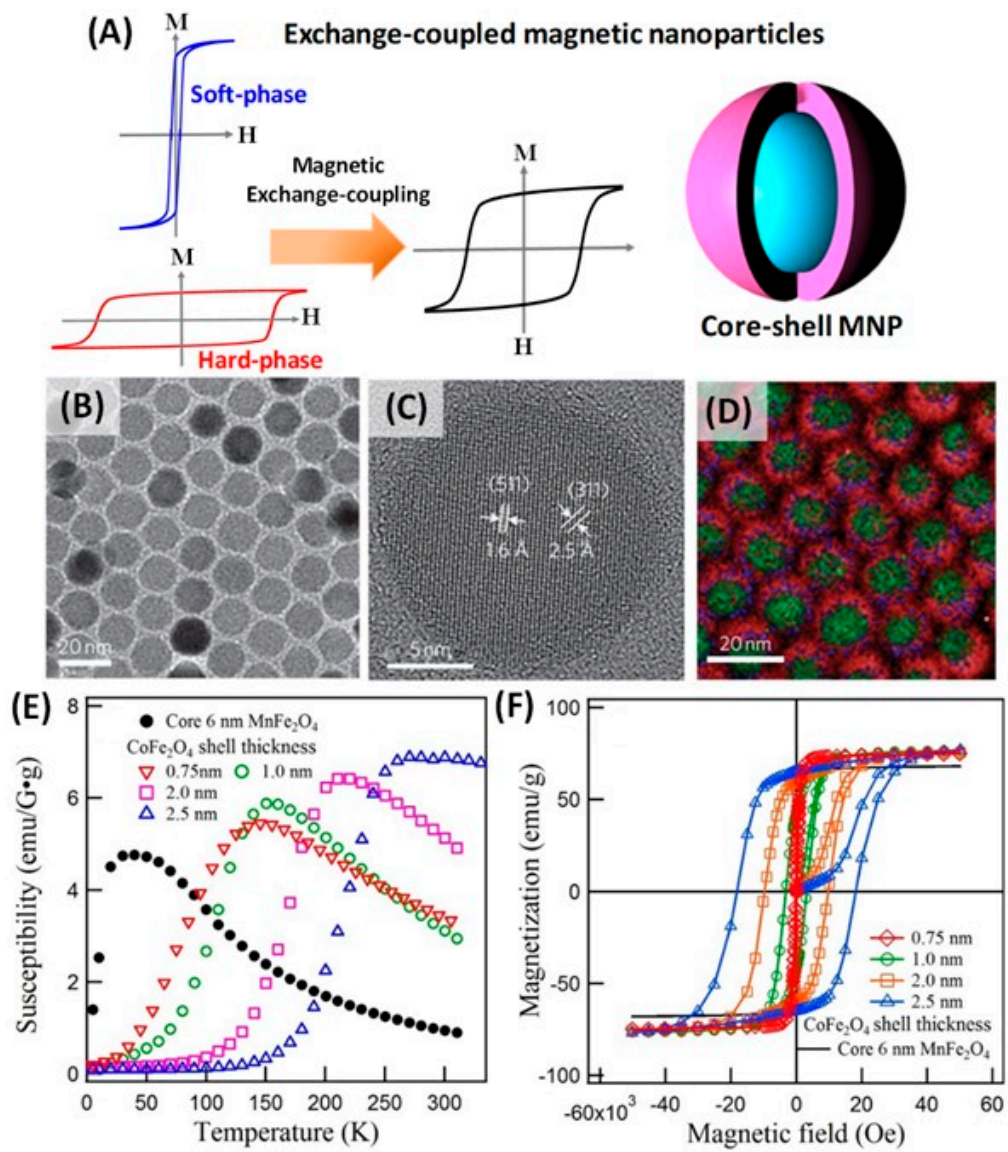

Figure 17. (A) A schematic depiction of the hysteresis loops for soft and hard nanoparticles and their possible combinations: exchange-coupled core-shell nanoparticles. (B) TEM image, (C) high-resolution TEM image of $15 \mathrm{~nm} \mathrm{CoFe} \mathrm{O}_{4} / \mathrm{MnFe}_{2} \mathrm{O}_{4}$ core-shell NPs and (D) Overlay of electron energy-loss spectrum mapped images of $\mathrm{Co}$ (green), Fe (red) and Mn (blue) [31]. (E) Temperature dependent susceptibility under $100 \mathrm{Oe}$ field and (F) hysteresis loops at $5 \mathrm{~K}$ for $\mathrm{MnFe}_{2} \mathrm{O}_{4} / \mathrm{CoFe}_{2} \mathrm{O}_{4}$ core-shell nanoparticles with variation of shell thickness as 0, 0.75, 1.0, 2.0 and $2.5 \mathrm{~nm}$ [139]. 
Recently, the exchange-coupled core-shell nanoparticles have been explored to modulate magnetic properties of the spinel ferrite and have shown substantial importance in biomedical applications $[139,140]$. By picking cobalt ferrites and/or other soft magnetic ferrites as starting materials, a core-shell structure with distinctly controllable uniformity and size dimensions can be acquired. In a typical synthesis of $\mathrm{CoFe}_{2} \mathrm{O}_{4} / \mathrm{MnFe}_{2} \mathrm{O}_{4}$ core-shell nanoparticles, the $\mathrm{CoFe}_{2} \mathrm{O}_{4} \mathrm{NPs}$ dispersed in hexane were injected into the mixture of $\mathrm{MnCl}_{2}, \mathrm{Fe}(\mathrm{acac})_{3}$, oleic acid and oleylamine [134]. The reaction was then refluxed at $365{ }^{\circ} \mathrm{C}$ for $1 \mathrm{~h}$ and $\mathrm{MnFe}_{2} \mathrm{O}_{4}$ was overgrown onto the surface of the $\mathrm{CoFe}_{2} \mathrm{O}_{4}$ seeds to form a core-shell structure. The same approach can be extended to synthesize other core-shell nanoparticles such as $\mathrm{CoFe}_{2} \mathrm{O}_{4} / \mathrm{Fe}_{3} \mathrm{O}_{4}, \mathrm{CoFe}_{2} \mathrm{O}_{4} / \mathrm{ZnFe}_{2} \mathrm{O}_{4}$ and $\mathrm{MnFe}_{2} \mathrm{O}_{4} / \mathrm{ZnFe}_{2} \mathrm{O}_{4}$. The core-shell structures can be confirmed from the high-resolution TEM and electron energy-loss spectrum (EELS) mapping analysis as shown in Figure 17B-D. Figure 17D shows superimposed EELS mapped images of $\mathrm{CoFe}_{2} \mathrm{O}_{4} / \mathrm{MnFe}_{2} \mathrm{O}_{4}$ nanoparticles. In this figure $\mathrm{Co}, \mathrm{Fe}$, and $\mathrm{Mn}$ are color-coded in green, red and blue respectively. While $\mathrm{Co}$ is present only in the core region of each nanoparticle, $\mathrm{Fe}$ is distributed throughout the nanoparticle, and Mn only on the shell. The exchange-coupled magnetism is confirmed from the enhanced coercivity and magnetic anisotropy values. At $5 \mathrm{~K}$, the $H_{C}$ for the $\mathrm{CoFe}_{2} \mathrm{O}_{4} / \mathrm{MnFe}_{2} \mathrm{O}_{4}$ nanoparticles falls between the values for $\mathrm{CoFe}_{2} \mathrm{O}_{4}$ and $\mathrm{MnFe}_{2} \mathrm{O}_{4}$ nanoparticles: $\mathrm{H}_{\mathrm{C}}\left(\mathrm{CoFe}_{2} \mathrm{O}_{4} / \mathrm{MnFe}_{2} \mathrm{O}_{4}\right)=2.53 \mathrm{kOe}, H_{C}\left(\mathrm{CoFe}_{2} \mathrm{O}_{4}\right)=11.6 \mathrm{kOe}$ and $H_{C}\left(\mathrm{MnFe}_{2} \mathrm{O}_{4}\right)=0$ Oe. Song et al. synthesized $\mathrm{MnFe}_{2} \mathrm{O}_{4} / \mathrm{CoFe}_{2} \mathrm{O}_{4}$ core-shell NPs with a core diameter of $6 \mathrm{~nm}$, and the shell thickness can be precisely controlled from 0.5 to $3 \mathrm{~nm}$ [139]. The relationship of the shell thickness with the blocking temperature and the coercivity of $\mathrm{MnFe}_{2} \mathrm{O}_{4} / \mathrm{CoFe}_{2} \mathrm{O}_{4}$ core-shell nanoparticles with changing the shell thickness from 0.5 to $3 \mathrm{~nm}$ are shown in Figure 17E,F. The blocking temperature and coercivity in the core-shell nanoparticles increase as the shell thickness increases.

From the above discussion we have noticed that the magnetic anisotropy, which plays a critical role in hyperthermia heating can be tuned by controlling the core-shell dimensions. Theoretical analysis discussed in the Section 2.2 confirmed that the SAR of superparamagnetic NPs could be optimized when the $K_{\text {eff }}$ will be in the range from $0.5 \times 10^{4}$ to $4.0 \times 10^{4} \mathrm{~J} / \mathrm{m}^{3}$ (i.e., the case of $2 \pi f \sim \tau^{-1}$ ), but the $M_{S}$ factor must also be considered in attempting to maximize the SAR. To attain the right $K_{\text {eff }}$ and $M_{S}$ combination, the exchange-coupled core-shell nanoparticles of hard/soft magnetic ferrites are important. A typical example is the core/shell nanoparticles composed of magnetically hard $\mathrm{CoFe}_{2} \mathrm{O}_{4}\left(\mathrm{~K}=2 \times 10^{5} \mathrm{~J} / \mathrm{m}^{3}\right)$ core and magnetically soft $\mathrm{MnFe}_{2} \mathrm{O}_{4}$ shell $\left(K=3 \times 10^{3} \mathrm{~J} / \mathrm{m}^{3}\right)$ [31]. The exchange coupled $\mathrm{CoFe}_{2} \mathrm{O}_{4} / \mathrm{MnFe}_{2} \mathrm{O}_{4}$ nanoparticles $(\sim 15 \mathrm{~nm}$ in size) preserved the superparamagnetism at room temperature and showed a $K_{\text {eff }}$ of $1.5 \times 10^{4} \mathrm{~J} / \mathrm{m}^{3}$, which is in the best possible $K_{\text {eff }}$ range. As a result, the core/shell nanoparticles exhibited 5 times higher SAR value of $2280 \mathrm{~W} / \mathrm{g}$ of magnetic elements compared to single component $\mathrm{NPs}\left(443 \mathrm{~W} / \mathrm{g}\right.$ for the $\mathrm{CoFe}_{2} \mathrm{O}_{4} \mathrm{NPs}$ and $411 \mathrm{~W} / \mathrm{g}$ for the $\mathrm{MnFe}_{2} \mathrm{O}_{4} \mathrm{NPs}$ ) in an ACMF of $H_{a c}=37.3 \mathrm{kA} / \mathrm{m}$ and $f=500 \mathrm{kHz}$ (Figure 18A). In addition, the SAR values can be tuned by varying the combination of the core and shell components as shown in Figure 18B,C. The magnetic coupling of core and shell components provides $K_{\text {eff }}$ values of $\sim 1.5 \times 10^{4}$ to $2.0 \times 10^{4} \mathrm{~J} / \mathrm{m}^{3}$, which fits in the optimal $K_{\text {eff }}$ range. Interestingly, the $\mathrm{Zn}_{0.4} \mathrm{Co}_{0.6} \mathrm{Fe}_{2} \mathrm{O}_{4} / \mathrm{Zn}_{0.4} \mathrm{Mn}_{0.6} \mathrm{Fe}_{2} \mathrm{O}_{4}$ NPs show an extremely high $M_{S}$ of $150 \mathrm{emu} / \mathrm{g}$ of magnetic elements and when used for hyperthermia heating it shows SAR around $3886 \mathrm{~W} / \mathrm{g}$ of magnetic elements. This is 1.7 times greater than that for $\mathrm{CoFe}_{2} \mathrm{O}_{4} / \mathrm{MnFe}_{2} \mathrm{O}_{4}$ and 34 times larger than that for Feridex, the commercial iron-oxide magnetic nanoparticle $(115 \mathrm{~W} / \mathrm{g})$. While the SAR values of core-shell nanoparticles are comparable to those of ferromagnetic and anisotropic nanoparticles, the advantage of core-shell nanoparticles over the latter's is that they exhibit superparamagnetism at room temperature, an important property for the clinical applications.

The in vivo hyperthermia treatment is performed by injecting $75 \mu \mathrm{g}$ of the $\mathrm{CoFe}_{2} \mathrm{O}_{4} / \mathrm{MnFe}_{2} \mathrm{O}_{4}$ core/shell nanoparticles into the U87MG human brain cancer cells in mice and then applying the ACMF for $10 \mathrm{~min}$. The tumor volume continuously shrinks with time, which is noticed for the core/shell NPs (Figure 18D). In fact, the tumor is eliminated after an 18 days hyperthermia treatment with the formulated core/shell NPs solution. While, the tumors volume did not shrink by using Feridex (commercial ferrofluid), or chemotherapeutic doxorubicin cancer drug under the similar treatments, 
but displayed growth behavior like the untreated control (Figure 18E). In short, these core-shell ferrites can be an effective new nanoscale tool beneficial for a variety of systems that rely on heat induction, including hyperthermia therapy and other advanced nanobiotechnology applications such as on-demand drug release and thermal activation of metabolic pathways within a single cell.
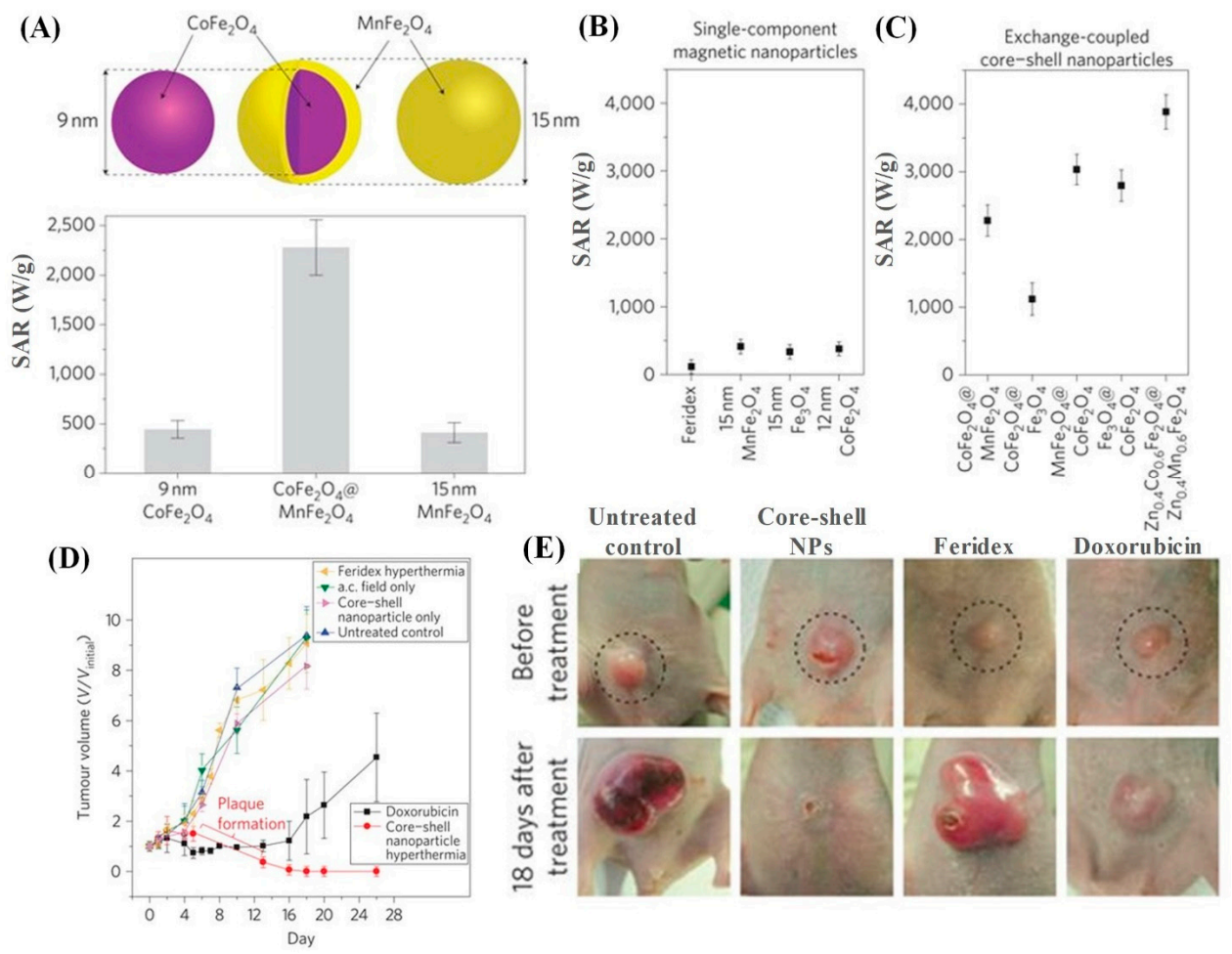

Figure 18. (A) Schematic view of $15 \mathrm{~nm} \mathrm{CoFe}{ }_{2} \mathrm{O}_{4} / \mathrm{MnFe}_{2} \mathrm{O}_{4}$ core/shell MNPs and its SAR value in comparison with the values for its components $\left(9 \mathrm{~nm} \mathrm{CoFe}_{2} \mathrm{O}_{4}\right.$ and $\left.15 \mathrm{~nm} \mathrm{MnFe} 2 \mathrm{O}_{4}\right)$. (B) SAR values of single-component magnetic NPs and (C) the various of SAR values of combinations of core-shell NPs. (D) Plot of tumor volume $\left(V / V_{\text {initial }}\right)$ versus days after hyperthermia treatment with the single-component and core-shell NPs. In the group treated with core-shell MNPs-based hyperthermia, the tumor was completely eliminated in 18 days. (E) Nude mice xenografted with cancer cells (U87MG) before treatment (upper row, dotted circle) and 18 days after treatment (lower row) with untreated control, $\mathrm{CoFe}_{2} \mathrm{O}_{4} @ \mathrm{MnFe}_{2} \mathrm{O}_{4}$-based hyperthermia, Feridex-based hyperthermia and doxorubicin, respectively [31].

\section{Conclusions}

In this review, the close correlations are discussed between the ferrite nanoparticles properties (magnetic and morphological) and the hyperthermia performance. The size, composition, shape, inter-particle interaction and inter-phase exchange coupling are utilized to tune the magnetic properties and consequently the heating performance of MNPs. The control over size from a nanometer to a submicron length scale and incorporation of different transition metal ions lead to the improvement of magnetic properties $\left(M_{S}\right.$ and $\left.K_{\text {eff }}\right)$. The size dependence of magnetic and inductive heating properties reveals that the large size $\mathrm{Fe}_{3} \mathrm{O}_{4}$ nanoparticles $(>16 \mathrm{~nm})$ are in ferromagnetic regime which gives extremely high SAR value above $800 \mathrm{~W} / \mathrm{g}$. Alternatively, the $M_{S}$ and $H_{C}$ are improved by introducing the shape anisotropy. Particularly, the iron oxide nanorods and nanocubes exhibit unprecedented heating ability compared to spherical nanoparticles of equivalent material volume. Besides, the collective magnetic response is achieved by modifying interaction strength between the nanoparticles. The nanostructures composed of number of magnetic domains such as, superlattice, nanoflowers and nanocrystal assemblies have also demonstrated efficient heating effect due to the cooperative magnetism among nanocrystals. Hard and soft ferrite core-shell architecture with strong 
exchange coupling optimizes $K_{\text {eff }}$ to an intermediate value of the soft and hard ferrites. The intermediate $K_{\text {eff }}$ value makes the nanoparticles relax with a frequency of ACMF, which enhances the SAR value to a surprisingly high value of $3886 \mathrm{~W} / \mathrm{g}$ of magnetic elements. The prominently high SAR values obtained via optimization of magnetic performance demonstrate the promising future of iron oxide nanoparticles for biomedical applications. Nevertheless, a long-term stability, toxicological impact, site-specific internalization and metabolism of the magnetic nanoparticles are still open questions and more extensive research is needed. Finally, new types of smart magnetic nanoparticles with multifunctional properties are still needed for cancer theranostics. A reproducible and large-scale synthesis approach of magnetic nanoparticles also needs to be established for the industry perspective. Although the described magnetic nanoparticles are functionalized with a suitable surfactant for the hyperthermia application, but it can also be further functionalized or decorated with various functional materials such as targeting molecules, biomarker/quantum dots, radioisotopes and drugs. The multifunctional magnetic nanoparticles will facilitate early diagnosis with multimodal imaging and simultaneous therapy.

Author Contributions: J.M. and J.P.L. conceptualized the review. J.M. wrote the first draft of this manuscript with substantial inputs from M.X. and J.P.L. All authors provided input, reviewed and finalized the manuscript.

Funding: This research received no external funding.

Conflicts of Interest: The authors declare no conflict of interest.

\section{References}

1. Jun, Y.W.; Seo, J.W.; Cheon, J. Nanoscaling laws of magnetic nanoparticles and their applicabilities in biomedical sciences. Acc. Chem. Res. 2008, 41, 179-189. [CrossRef] [PubMed]

2. Noh, S.H.; Na, W.; Jang, J.T.; Lee, J.H.; Lee, E.J.; Moon, S.H.; Lim, Y.; Shin, J.S.; Cheon, J. Nanoscale magnetism control via surface and exchange anisotropy for optimized ferrimagnetic hysteresis. Nano Lett. 2012, 12, 3716-3721. [CrossRef] [PubMed]

3. Reiss, G.; Hütten, A. Magnetic nanoparticles: Applications beyond data storage. Nat. Mater. 2005, 4, 725-726. [CrossRef] [PubMed]

4. Jun, Y.W.; Huh, Y.M.; Choi, J.S.; Lee, J.-H.; Song, H.T.; Kim, S.; Kim, S.; Yoon, S.; Kim, K.S.; Shin, J.S. Nanoscale size effect of magnetic nanocrystals and their utilization for cancer diagnosis via magnetic resonance imaging. J. Am. Chem. Soc. 2005, 127, 5732-5733. [CrossRef]

5. Zhao, Z.; Zhou, Z.; Bao, J.; Wang, Z.; Hu, J.; Chi, X.; Ni, K.; Wang, R.; Chen, X.; Chen, Z. Octapod iron oxide nanoparticles as high-performance $\mathrm{T} 2$ contrast agents for magnetic resonance imaging. Nat. Commun. 2013, 4. [CrossRef]

6. Lee, J.H.; Huh, Y.M.; Jun, Y.W.; Seo, J.-W.; Jang, J.T.; Song, H.T.; Kim, S.; Cho, E.J.; Yoon, H.G.; Suh, J.S. Artificially engineered magnetic nanoparticles for ultra-sensitive molecular imaging. Nat. Med. 2007, 13, 95-99. [CrossRef] [PubMed]

7. Bedanta, S.; Kleemann, W. Supermagnetism. J. Phys. D Appl. Phys. 2009, 42, 013001. [CrossRef]

8. De Toro, J.A.; Lee, S.S.; Salazar, D.; Cheong, J.L.; Normile, P.S.; Muñiz, P.; Riveiro, J.M.; Hillenkamp, M.; Tournus, F.; Tamion, A.; et al. A nanoparticle replica of the spin-glass state. Appl. Phys. Lett. 2013, 102, 183104. [CrossRef]

9. Aslibeiki, B.; Kameli, P.; Salamati, H.; Eshraghi, M.; Tahmasebi, T. Superspin glass state in $\mathrm{MnFe}_{2} \mathrm{O}_{4}$ nanoparticles. J. Magn. Magn. Mater. 2010, 322, 2929-2934. [CrossRef]

10. Park, J.I.; Kang, N.J.; Jun, Y.W.; Oh, S.J.; Ri, H.C.; Cheon, J. Superlattice and Magnetism Directed by the Size and Shape of Nanocrystals. Chem. Phys. Chem. 2002, 3, 543-547. [CrossRef]

11. Gao, J.; Gu, H.; Xu, B. Multifunctional magnetic nanoparticles: Design, synthesis, and biomedical applications. Acc. Chem. Res. 2009, 42, 1097-1107. [CrossRef] [PubMed]

12. Gallo, J.; Long, N.J.; Aboagye, E.O. Magnetic nanoparticles as contrast agents in the diagnosis and treatment of cancer. Chem. Soc. Rev. 2013, 42, 7816-7833. [CrossRef] [PubMed]

13. Dobson, J. Magnetic nanoparticles for drug delivery. Drug Dev. Res. 2006, 67, 55-60. [CrossRef] 
14. McCarthy, J.R.; Weissleder, R. Multifunctional magnetic nanoparticles for targeted imaging and therapy. Adv. Drug Deliv. Rev. 2008, 60, 1241-1251. [CrossRef] [PubMed]

15. Pankhurst, Q.; Thanh, N.; Jones, S.; Dobson, J. Progress in applications of magnetic nanoparticles in biomedicine. J. Phys. D Appl. Phys. 2009, 42, 224001. [CrossRef]

16. Akbarzadeh, A.; Samiei, M.; Davaran, S. Magnetic nanoparticles: Preparation, physical properties, and applications in biomedicine. Nanoscale Res. Lett. 2012, 7, 144. [CrossRef] [PubMed]

17. Colombo, M.; Carregal-Romero, S.; Casula, M.F.; Gutiérrez, L.; Morales, M.P.; Böhm, I.B.; Heverhagen, J.T.; Prosperi, D.; Parak, W.J. Biological applications of magnetic nanoparticles. Chem. Soc. Rev. 2012, 41, 4306-4334. [CrossRef] [PubMed]

18. Hao, R.; Xing, R.; Xu, Z.; Hou, Y.; Gao, S.; Sun, S. Synthesis, functionalization, and biomedical applications of multifunctional magnetic nanoparticles. Adv. Mater. 2010, 22, 2729-2742. [CrossRef] [PubMed]

19. Martinez-Boubeta, C.; Simeonidis, K.; Makridis, A.; Angelakeris, M.; Iglesias, O.; Guardia, P.; Cabot, A.; Yedra, L.; Estrade, S.; Peiro, F.; et al. Learning from nature to improve the heat generation of iron-oxide nanoparticles for magnetic hyperthermia applications. Sci. Rep. 2013, 3, 1652. [CrossRef]

20. Kappiyoor, R.; Liangruksa, M.; Ganguly, R.; Puri, I.K. The effects of magnetic nanoparticle properties on magnetic fluid hyperthermia. J. Appl. Phys. 2010, 108, 094702. [CrossRef]

21. Barick, K.C.; Aslam, M.; Lin, Y.-P.; Bahadur, D.; Prasad, P.V.; Dravid, V.P. Novel and efficient MR active aqueous colloidal $\mathrm{Fe}_{3} \mathrm{O}_{4}$ nanoassemblies. J. Mater. Chem. 2009, 19, 7023-7029. [CrossRef]

22. Barick, K.C.; Singh, S.; Bahadur, D.; Lawande, M.A.; Patkar, D.P.; Hassan, P.A. Carboxyl decorated $\mathrm{Fe}_{3} \mathrm{O}_{4}$ nanoparticles for MRI diagnosis and localized hyperthermia. J. Colloid Interface Sci. 2014, 418, 120-125. [CrossRef] [PubMed]

23. Guardia, P.; Di Corato, R.; Lartigue, L.; Wilhelm, C.; Espinosa, A.; Garcia-Hernandez, M.; Gazeau, F.; Manna, L.; Pellegrino, T. Water-soluble iron oxide nanocubes with high values of specific absorption rate for cancer cell hyperthermia treatment. ACS Nano 2012, 6, 3080-3091. [CrossRef] [PubMed]

24. Hugounenq, P.; Levy, M.; Alloyeau, D.; Lartigue, L.; Dubois, E.; Cabuil, V.; Ricolleau, C.; Roux, S.; Wilhelm, C.; Gazeau, F.; et al. Iron oxide monocrystalline nanoflowers for highly efficient magnetic hyperthermia. Phys. Chem. C 2012, 116, 15702-15712. [CrossRef]

25. Lartigue, L.; Hugounenq, P.; Alloyeau, D.; Clarke, S.P.; Lévy, M.; Bacri, J.C.; Bazzi, R.; Brougham, D.F.; Wilhelm, C.; Gazeau, F. Cooperative organization in iron oxide multi-core nanoparticles potentiates their efficiency as heating mediators and MRI contrast agents. ACS Nano 2012, 6, 10935-10949. [CrossRef]

26. Wu, W.; Jiang, C.Z.; Roy, V.A.L. Designed synthesis and surface engineering strategies of magnetic iron oxide nanoparticles for biomedical applications. Nanoscale 2016, 8, 19421-19474. [CrossRef]

27. Gupta, A.K.; Gupta, M. Synthesis and surface engineering of iron oxide nanoparticles for biomedical applications. Biomaterials 2005, 26, 3995-4021. [CrossRef]

28. Arami, H.; Khandhar, A.; Liggitt, D.; Krishnan, K.M. In vivo delivery, pharmacokinetics, biodistribution and toxicity of iron oxide nanoparticles. Chem. Soc. Rev. 2015, 44, 8576-8607. [CrossRef]

29. Lee, N.; Yoo, D.; Ling, D.; Cho, M.H.; Hyeon, T.; Cheon, J. Iron oxide-based nanoparticles for multimodal imaging and magnetoresponsive therapy. Chem. Rev. 2015, 115, 10637-10689. [CrossRef]

30. Pilati, V.; Cabreira Gomes, R.; Gomide, G.; Coppola, P.; Silva, F.G.; Paula, F.L.O.; Perzynski, R.; Goya, G.F.; Aquino, R.; Depeyrot, J. Core/Shell nanoparticles of non-stoichiometric Zn-Mn and Zn-Co ferrites as thermosensitive heat sources for magnetic fluid hyperthermia. J. Phys. Chem. C 2018, 122, 3028-3038. [CrossRef]

31. Lee, J.H.; Jang, J.T.; Choi, J.S.; Moon, S.H.; Noh, S.H.; Kim, J.W.; Kim, J.G.; Kim, I.S.; Park, K.I.; Cheon, J. Exchange-coupled magnetic nanoparticles for efficient heat induction. Nat. Nanotechnol. 2011, 6, 418-422. [CrossRef] [PubMed]

32. Yin, P.T.; Shah, S.; Pasquale, N.J.; Garbuzenko, O.B.; Minko, T.; Lee, K.B. Stem cell-based gene therapy activated using magnetic hyperthermia to enhance the treatment of cancer. Biomaterials 2016, 81, 46-57. [CrossRef] [PubMed]

33. Park, J.; An, K.; Hwang, Y.; Park, J.G.; Noh, H.-J.; Kim, J.Y.; Park, J.H.; Hwang, N.M.; Hyeon, T. Ultra-large-scale syntheses of monodisperse nanocrystals. Nat. Mater. 2004, 3, 891-895. [CrossRef] [PubMed]

34. Thanh, N.T. Magnetic Nanoparticles: From Fabrication to Clinical Applications; CRC Press: Boca Raton, FL, USA, 2012. 
35. Mohapatra, J.; Liu, J.P. Chapter 1 - Rare-earth-free permanent magnets: the past and future. In Handbook of Magnetic Materials; Brück, E., Ed.; Elsevier: Amsterdam, The Netherlands, 2018; Volume 27, pp. 1-57.

36. Guimarães, A.P. Principles of Nanomagnetism; Springer: Berlin/Heidelberg, Germany, 2009.

37. Sorensen, C. Magnetism; Klabunde, K.J., Ed.; John Wiley \& Sons, Inc.: Hoboken, NJ, USA, 2001; pp. $169-221$.

38. Goya, G.F.; Berquó, T.S.; Fonseca, F.C.; Morales, M.P. Static and dynamic magnetic properties of spherical magnetite nanoparticles. J. Appl. Phys. 2003, 94, 3520-3528. [CrossRef]

39. Krishnan, K.M. Biomedical nanomagnetics: A spin through possibilities in imaging, diagnostics, and therapy. IEEE Trans. Magn. 2010, 46, 2523-2558. [CrossRef] [PubMed]

40. Cullity, B.D.; Graham, C.D. Introduction to Magnetic Materials; John Wiley \& Sons: Hoboken, NJ, USA, 2011; p. 386.

41. Dormann, J.; Fiorani, D.; Tronc, E. Magnetic relaxation in fine-particle systems. Adv. Chem. Phys. 1997, 98, 283-494.

42. Chamberlin, R.V.; Humfeld, K.D.; Farrell, D.; Yamamuro, S.; Ijiri, Y.; Majetich, S.A. Magnetic relaxation of iron nanoparticles. J. Appl. Phys. 2002, 91, 6961-6963. [CrossRef]

43. Mohapatra, J.; Mitra, A.; Bahadur, D.; Aslam, M. Superspin glass behavior of self-interacting $\mathrm{CoFe}_{2} \mathrm{O}_{4}$ nanoparticles. J. Alloys Compd. 2015, 628, 416-423. [CrossRef]

44. Cyrot, M. A possible origin for the Vogel-Fulcher law. Phys. Lett. A 1981, 83, 275-278. [CrossRef]

45. Shtrikman, S.; Wohlfarth, E.P. The theory of the Vogel-Fulcher law of spin glasses. Phys. Lett. A 1981, 85, 467-470. [CrossRef]

46. Majetich, S.A.; Wen, T.; Booth, R.A. Functional magnetic nanoparticle assemblies: Formation, collective behavior, and future directions. ACS Nano 2011, 5, 6081-6084. [CrossRef] [PubMed]

47. Yamamoto, K.; Hogg, C.R.; Yamamuro, S.; Hirayama, T.; Majetich, S.A. Dipolar ferromagnetic phase transition in Fe 3 O 4 nanoparticle arrays observed by Lorentz microscopy and electron holography. Appl. Phys. Lett. 2011, 98. [CrossRef]

48. Varón, M.; Beleggia, M.; Kasama, T.; Harrison, R.; Dunin-Borkowski, R.; Puntes, V.; Frandsen, C. Dipolar magnetism in ordered and disordered low-dimensional nanoparticle assemblies. Sci. Rep. 2013, 3, 1234. [CrossRef]

49. Cruz, M.M.; Ferreira, L.P.; Alves, A.F.; Mendo, S.G.; Ferreira, P.; Godinho, M.; Carvalho, M.D. Chapter 19 Nanoparticles for magnetic hyperthermia. In Nanostructures for Cancer Therapy; Ficai, A., Grumezescu, A.M., Eds.; Elsevier: Amsterdam, The Netherlands, 2017; pp. 485-511.

50. Deatsch, A.E.; Evans, B.A. Heating efficiency in magnetic nanoparticle hyperthermia. J. Magn. Magn. Mater. 2014, 354, 163-172. [CrossRef]

51. Shaterabadi, Z.; Nabiyouni, G.; Soleymani, M. Physics responsible for heating efficiency and self-controlled temperature rise of magnetic nanoparticles in magnetic hyperthermia therapy. Prog. Biophys. Mol. Biol. 2018, 133, 9-19. [CrossRef] [PubMed]

52. Hergt, R.; Dutz, S.; Röder, M. Effects of size distribution on hysteresis losses of magnetic nanoparticles for hyperthermia. J. Phys. Condens. Matter. 2008, 20. [CrossRef]

53. Verde, E.L.; Landi, G.T.; Gomes, J.A.; Sousa, M.H.; Bakuzis, A.F. Magnetic hyperthermia investigation of cobalt ferrite nanoparticles: Comparison between experiment, linear response theory, and dynamic hysteresis simulations. J. Appl. Phys. 2012, 111. [CrossRef]

54. Rosensweig, R.E. Heating magnetic fluid with alternating magnetic field. J. Mag. Mag. Mater. 2002, 252, 370-374. [CrossRef]

55. Liu, F.; Hou, Y.; Gao, S. Exchange-coupled nanocomposites: Chemical synthesis, characterization and applications. Chem. Soc. Rev. 2014, 43, 8098-8113. [CrossRef]

56. Abenojar, E.C.; Wickramasinghe, S.; Bas-Concepcion, J.; Samia, A.C.S. Structural effects on the magnetic hyperthermia properties of iron oxide nanoparticles. Prog. Natl. Sci. Mater. Int. 2016, 26, 440-448. [CrossRef]

57. Mamiya, H. Recent advances in understanding magnetic nanoparticles in ac magnetic fields and optimal design for targeted hyperthermia. J. Nanomater. 2013, 2013, 752973. [CrossRef]

58. Hanini, A.; Lartigue, L.; Gavard, J.; Kacem, K.; Wilhelm, C.; Gazeau, F.; Chau, F.; Ammar, S. Zinc substituted ferrite nanoparticles with $\mathrm{Zn}_{0.9} \mathrm{Fe}_{2.1} \mathrm{O}_{4}$ formula used as heating agents for in vitro hyperthermia assay on glioma cells. J. Magn. Magn. Mater. 2016, 416, 315-320. [CrossRef] 
59. Oumezzine, E.; Hcini, S.; Baazaoui, M.; Hlil, E.K.; Oumezzine, M. Structural, magnetic and magnetocaloric properties of $\mathrm{Zn0}$. 6- $\mathrm{xNixCu0.} 4 \mathrm{Fe} 2 \mathrm{O} 4$ ferrite nanoparticles prepared by Pechini sol-gel method. Powder Technol. 2015, 278, 189-195. [CrossRef]

60. Srivastava, M.; Alla, S.K.; Meena, S.S.; Gupta, N.; Mandal, R.K.; Prasad, N.K. $\mathrm{Zn}_{\mathrm{x}} \mathrm{Fe}_{3-\mathrm{x}} \mathrm{O}_{4}(0.01 \leq \mathrm{x} \leq 0.8)$ nanoparticles for controlled magnetic hyperthermia application. N. J. Chem. 2018, 42, 7144-7153. [CrossRef]

61. Ferk, G.; Drofenik, M.; Lisjak, D.; Hamler, A.; Jagličić, Z.; Makovec, D. Synthesis and characterization of $\mathrm{Mg}_{1+{ }_{x}} \mathrm{Fe}_{2-2 x} \mathrm{Ti}_{x} \mathrm{O}_{4}$ nanoparticles with an adjustable Curie point. J. Magn. Magn. Mater. 2014, 350, $124-128$. [CrossRef]

62. Aslibeiki, B. Nanostructural, magnetic and electrical properties of Ag doped Mn-ferrite nanoparticles. Curr. Appl. Phys. 2014, 14, 1659-1664. [CrossRef]

63. Jadhav, S.V.; Kim, B.M.; Lee, H.Y.; Im, I.C.; Rokade, A.A.; Park, S.S.; Patil, M.P.; Kim, G.D.; Yu, Y.S.; Lee, S.H. Induction heating and in vitro cytotoxicity studies of $\mathrm{MnZnFe}_{2} \mathrm{O}_{4}$ nanoparticles for self-controlled magnetic particle hyperthermia. J. Alloys Compd. 2018, 745, 282-291. [CrossRef]

64. Park, J.; Lee, E.; Hwang, N.M.; Kang, M.; Kim, S.C.; Hwang, Y.; Park, J.G.; Noh, H.J.; Kim, J.Y.; Park, J.H.; et al. One-nanometer-scale size-controlled synthesis of monodisperse magnetic Iron oxide nanoparticles. Angew. Chem. Int. Ed. 2005, 44, 2872-2877. [CrossRef]

65. Sun, S.; Zeng, H. Size-controlled synthesis of magnetite nanoparticles. J. Am. Chem. Soc. 2002, 124, 8204-8205. [CrossRef]

66. Sun, S.; Zeng, H.; Robinson, D.B.; Raoux, S.; Rice, P.M.; Wang, S.X.; Li, G. Monodisperse $\mathrm{MFe}_{2} \mathrm{O}_{4}(\mathrm{M}=\mathrm{Fe}$, Co, Mn) nanoparticles. J. Am. Chem. Soc. 2004, 126, 273-279. [CrossRef]

67. Xu, Z.; Shen, C.; Hou, Y.; Gao, H.; Sun, S. Oleylamine as both reducing agent and stabilizer in a facile synthesis of magnetite nanoparticles. Chem. Mater. 2009, 21, 1778-1780. [CrossRef]

68. Mitra, A.; Mohapatra, J.; Meena, S.S.; Tomy, C.V.; Aslam, M. Verwey transition in ultrasmall-sized octahedral Fe3O4 nanoparticles. J. Phys. Chem. C 2014, 118, 19356-19362. [CrossRef]

69. Mohapatra, J.; Mitra, A.; Tyagi, H.; Bahadur, D.; Aslam, M. Iron oxide nanorods as high-performance magnetic resonance imaging contrast agents. Nanoscale 2015, 7, 9174-9184. [CrossRef] [PubMed]

70. Mohapatra, J.; Nigam, S.; Gupta, J.; Mitra, A.; Aslam, M.; Bahadur, D. Enhancement of magnetic heating efficiency in size controlled $\mathrm{MFe}_{2} \mathrm{O}_{4}(\mathrm{M}=\mathrm{Mn}, \mathrm{Fe}, \mathrm{Co}$ and Ni) nanoassemblies. RSC Adv. 2015, 5, 14311-14321. [CrossRef]

71. Mohapatra, J.; Zeng, F.; Elkins, K.; Xing, M.; Ghimire, M.; Yoon, S.; Mishra, S.R.; Liu, J.P. Size-dependent magnetic and inductive heating properties of $\mathrm{Fe}_{3} \mathrm{O}_{4}$ nanoparticles: Scaling laws across the superparamagnetic size. Phys. Chem. Chem. Phys. 2018, 20, 12879-12887. [CrossRef] [PubMed]

72. Lin, C.R.; Chiang, R.-K.; Wang, J.-S.; Sung, T.-W. Magnetic properties of monodisperse iron oxide nanoparticles. J. Appl. Phys. 2006, 99, 08N710. [CrossRef]

73. Daou, T.J.; Grenèche, J.M.; Pourroy, G.; Buathong, S.; Derory, A.; Ulhaq-Bouillet, C.; Donnio, B.; Guillon, D.; Begin-Colin, S. Coupling agent effect on magnetic properties of functionalized magnetite-based nanoparticles. Chem. Mater. 2008, 20, 5869-5875. [CrossRef]

74. Papaefthymiou, G.C. Nanoparticle magnetism. Nano Today 2009, 4, 438-447. [CrossRef]

75. Kim, B.H.; Lee, N.; Kim, H.; An, K.; Park, Y.I.; Choi, Y.; Shin, K.; Lee, Y.; Kwon, S.G.; Na, H.B. Large-scale synthesis of uniform and extremely small-sized iron oxide nanoparticles for high-resolution $\mathrm{T} 1$ magnetic resonance imaging contrast agents. J. Am. Chem Soc. 2011, 133, 12624-12631. [CrossRef]

76. Tong, S.; Quinto, C.A.; Zhang, L.; Mohindra, P.; Bao, G. Size-dependent heating of magnetic iron oxide nanoparticles. ACS Nano 2017, 11, 6808-6816. [CrossRef]

77. Demortière, A.; Panissod, P.; Pichon, B.P.; Pourroy, G.; Guillon, D.; Donnio, B.; Bégin-Colin, S. Size-dependent properties of magnetic iron oxide nanocrystals. Nanoscale 2011, 3, 225-232. [CrossRef] [PubMed]

78. Baaziz, W.; Pichon, B.P.; Fleutot, S.; Liu, Y.; Lefevre, C.; Greneche, J.M.; Toumi, M.; Mhiri, T.; Begin-Colin, S. Magnetic iron oxide nanoparticles: Reproducible tuning of the size and nanosized-dependent composition, defects, and spin canting. J. Phys. Chem. C 2014, 118, 3795-3810. [CrossRef]

79. Kim, T.; Lim, S.; Hong, J.; Kwon, S.G.; Okamoto, J.; Chen, Z.Y.; Jeong, J.; Kang, S.; Leiner, J.C.; Lim, J.T.; et al. Giant thermal hysteresis in Verwey transition of single domain $\mathrm{Fe}_{3} \mathrm{O}_{4}$ nanoparticles. Sci. Rep. 2018, 8, 5092. [CrossRef] [PubMed]

80. Habib, A.H.; Ondeck, C.L.; Chaudhary, P.; Bockstaller, M.R.; McHenry, M.E. Evaluation of iron-cobalt/ferrite core-shell nanoparticles for cancer thermotherapy. J. Appl. Phys. 2008, 103. [CrossRef] 
81. Vreeland, E.C.; Watt, J.; Schober, G.B.; Hance, B.G.; Austin, M.J.; Price, A.D.; Fellows, B.D.; Monson, T.C.; Hudak, N.S.; Maldonado-Camargo, L.; et al. Enhanced nanoparticle size control by extending LaMer's mechanism. Chem. Mater. 2015, 27, 6059-6066. [CrossRef]

82. Yamamoto, Y.; Horiuchi, K.; Takeuchi, M.; Tanaka, N.; Aihara, R.; Takeuchi, N.; Fujita, S. Size dependence study on magnetic heating properties of superparamagnetic iron oxide nanoparticles suspension. J. Appl. Phys. 2014, 116, 123906. [CrossRef]

83. Gonzales-Weimuller, M.; Zeisberger, M.; Krishnan, K.M. Size-dependant heating rates of iron oxide nanoparticles for magnetic fluid hyperthermia. J. Magn. Magn. Mater. 2009, 321, 1947-1950. [CrossRef] [PubMed]

84. Lima, E.; Torres, T.E.; Rossi, L.M.; Rechenberg, H.R.; Berquo, T.S.; Ibarra, A.; Marquina, C.; Ibarra, M.R.; Goya, G.F. Size dependence of the magnetic relaxation and specific power absorption in iron oxide nanoparticles. J. Nanopart. Res. 2013, 15, 1654. [CrossRef]

85. De la Presa, P.; Luengo, Y.; Multigner, M.; Costo, R.; Morales, M.; Rivero, G.; Hernando, A. Study of heating efficiency as a function of concentration, size, and applied field in $\gamma-\mathrm{Fe}_{2} \mathrm{O}_{3}$ nanoparticles. J. Phys. Chem. C 2012, 116, 25602-25610. [CrossRef]

86. Levy, M.; Quarta, A.; Espinosa, A.; Figuerola, A.; Wilhelm, C.; García-Hernández, M.; Genovese, A.; Falqui, A.; Alloyeau, D.; Buonsanti, R. Correlating magneto-structural properties to hyperthermia performance of highly monodisperse iron oxide nanoparticles prepared by a seeded-growth route. Chem. Mater. 2011, 23, 4170-4180. [CrossRef]

87. Ruta, S.; Chantrell, R.; Hovorka, O. Unified model of hyperthermia via hysteresis heating in systems of interacting magnetic nanoparticles. Sci. Rep. 2015, 5, 9090. [CrossRef] [PubMed]

88. Conde-Leboran, I.; Baldomir, D.; Martinez-Boubeta, C.; Chubykalo-Fesenko, O.; del Puerto Morales, M.; Salas, G.; Cabrera, D.; Camarero, J.; Teran, F.J.; Serantes, D. A single picture explains diversity of hyperthermia response of magnetic nanoparticles. J. Phys. Chem. C 2015, 119, 15698-15706. [CrossRef]

89. Das, R.; Alonso, J.; Nemati Porshokouh, Z.; Kalappattil, V.; Torres, D.; Phan, M.-H.; Garaio, E.; García, J.Á.; Sanchez Llamazares, J.L.; Srikanth, H. Tunable high aspect ratio iron oxide nanorods for enhanced hyperthermia. J. Phys. Chem. C 2016, 120, 10086-10093. [CrossRef]

90. Spaldin, N.A. Magnetic Materials: Fundamentals and Applications; Cambridge University Press: Cambridge, UK, 2010.

91. Goldman, A. Modern Ferrite Technology; Springer Science \& Business Media: Berlin/Heidelberg, Germany, 2006.

92. Mohapatra, J.; Mitra, A.; Bahadur, D.; Aslam, M. Surface controlled synthesis of $\mathrm{MFe}_{2} \mathrm{O}_{4}(\mathrm{M}=\mathrm{Mn}, \mathrm{Fe}, \mathrm{Co}, \mathrm{Ni}$ and $\mathrm{Zn)} \mathrm{nanoparticles} \mathrm{and} \mathrm{their} \mathrm{magnetic} \mathrm{characteristics.} \mathrm{CrystEngComm} \mathrm{2013,} \mathrm{15,} \mathrm{524-532.} \mathrm{[CrossRef]}$

93. Seisuke, N.; Koji, F.; Katsuhisa, T.; Kazuyuki, H. High magnetization and the high-temperature superparamagnetic transition with intercluster interaction in disordered zinc ferrite thin film. J. Phys. Condens. Matter. 2005, 17, 137.

94. Buschow, K.H.J. Handbook of Magnetic Materials; Elsevier: Amsterdam, The Netherlands, 2003.

95. Liu, C.; Zhang, Z.J. Size-dependent superparamagnetic properties of Mn spinel ferrite nanoparticles synthesized from reverse micelles. Chem. Mater. 2001, 13, 2092-2096. [CrossRef]

96. Song, Q.; Zhang, Z.J. Correlation between spin- orbital coupling and the superparamagnetic properties in magnetite and cobalt ferrite spinel nanocrystals. J. Phys. Chem. B 2006, 110, 11205-11209. [CrossRef]

97. Joshi, H.M.; Lin, Y.P.; Aslam, M.; Prasad, P.V.; Schultz-Sikma, E.A.; Edelman, R.; Meade, T.; Dravid, V.P. Effects of shape and size of cobalt ferrite nanostructures on their MRI contrast and thermal activation. J. Phys. Chem. C 2009, 113, 17761-17767. [CrossRef]

98. Fantechi, E.; Innocenti, C.; Albino, M.; Lottini, E.; Sangregorio, C.J. Influence of cobalt doping on the hyperthermic efficiency of magnetite nanoparticles. J. Magn. Magn. Mater. 2015, 380, 365-371. [CrossRef]

99. Sathya, A.; Guardia, P.; Brescia, R.; Silvestri, N.; Pugliese, G.; Nitti, S.; Manna, L.; Pellegrino, T. Cox $\mathrm{Fe}_{3-x}$ $\mathrm{O}_{4}$ nanocubes for theranostic applications: Effect of cobalt content and particle size. Chem. Mater. 2016, 28, 1769-1780. [CrossRef]

100. Mohapatra, J.; Xing, M.; Liu, J.P. Magnetic and hyperthermia properties of $\mathrm{Co}_{\mathrm{x}} \mathrm{Fe}_{3-\mathrm{x}} \mathrm{O}_{4}$ nanoparticles synthesized via cation exchange. AIP Adv. 2018, 8, 056725. [CrossRef]

101. Ma, Y.; Xia, J.; Yao, C.; Yang, F.; Stanciu, S.G.; Li, P.; Jin, Y.; Chen, T.; Zheng, J.; Chen, G.; et al. Precisely Tuning the Contrast Properties of $\mathrm{Zn}_{x} \mathrm{Fe}_{3-\mathrm{x}} \mathrm{O}_{4}$ Nanoparticles in Magnetic Resonance Imaging by Controlling Their Doping Content and Size. Chem. Mater. 2019. [CrossRef] 
102. Yang, Z.; Li, Z.; Yang, Y.; Xu, Z.J. Optimization of $\mathrm{Zn}_{\mathrm{x}} \mathrm{Fe}_{3-\mathrm{x}} \mathrm{O}_{4}$ hollow spheres for enhanced microwave Attenuation. ACS Appl. Mater. Interfaces 2014, 6, 21911-21915. [CrossRef] [PubMed]

103. Michael, F. Ferromagnetic resonance of ultrathin metallic layers. Rep. Prog. Phys. 1998, 61. [CrossRef]

104. Zhou, Z.; Zhu, X.; Wu, D.; Chen, Q.; Huang, D.; Sun, C.; Xin, J.; Ni, K.; Gao., J. Anisotropic shaped iron oxide nanostructures: Controlled synthesis and proton relaxation shortening effects. J. Chem. Mater. 2015, 27, 3505-3515. [CrossRef]

105. Jiang, C.; Leung, C.W.; Pong, P.W.T. Magnetic-field-assisted assembly of anisotropic superstructures by iron oxide nanoparticles and their enhanced magnetism. Nanoscale Res. Lett. 2016, 11. [CrossRef]

106. McGrath, A.J.; Cheong, S.; Henning, A.M.; Gooding, J.J.; Tilley, R.D. Size and shape evolution of highly magnetic iron nanoparticles from successive growth reactions. Chem. Commun. 2017, 53, 11548-11551. [CrossRef]

107. Nikitin, A.; Khramtsov, M.; Garanina, A.; Mogilnikov, P.; Sviridenkova, N.; Shchetinin, I.; Savchenko, A.; Abakumov, M.; Majouga, A. Synthesis of iron oxide nanorods for enhanced magnetic hyperthermia. J. Magn. Magn. Mater. 2019, 469, 443-449. [CrossRef]

108. Kloust, H.; Zierold, R.; Merkl, J.P.; Schmidtke, C.; Feld, A.; Pöselt, E.; Kornowski, A.; Nielsch, K.; Weller, H. Synthesis of iron oxide nanorods using a template mediated approach. Chem. Mater. 2015, 27, 4914-4917. [CrossRef]

109. Orza, A.; Wu, H.; Xu, Y.; Lu, Q.; Mao, H. One-step facile synthesis of highly magnetic and surface functionalized iron oxide nanorods for biomarker-targeted applications. ACS Appl. Mater. Interfaces 2017, 9, 20719-20727. [CrossRef]

110. Guardia, P.; Labarta, A.; Batlle, X.J. Tuning the size, the shape, and the magnetic properties of iron oxide nanoparticles. Phys. Chem. C 2011, 115, 390-396. [CrossRef]

111. Gandha, K.; Mohapatra, J.; Hossain, M.K.; Elkins, K.; Poudyal, N.; Rajeshwar, K.; Liu, J.P. Mesoporous iron oxide nanowires: Synthesis, magnetic and photocatalytic properties. RSC Adv. 2016, 6, 90537-90546. [CrossRef]

112. Jiao, F.; Jumas, J.C.; Womes, M.; Chadwick, A.V.; Harrison, A.; Bruce, P.G. Synthesis of Ordered Mesoporous $\mathrm{Fe}_{3} \mathrm{O}_{4}$ and $\gamma-\mathrm{Fe}_{2} \mathrm{O}_{3}$ with Crystalline Walls Using Post-Template Reduction/Oxidation. J. Am. Chem. Soc. 2006, 128, 12905-12909. [CrossRef] [PubMed]

113. Han, Q.; Liu, Z.; Xu, Y.; Zhang, H. Synthesis and magnetic properties of single-crystalline magnetite nanowires. J. Cryst. Growth 2007, 307, 483-489. [CrossRef]

114. Terrier, C.; Abid, M.; Arm, C.; Serrano-Guisan, S.; Gravier, L.; Ansermet, J.P. $\mathrm{Fe}_{3} \mathrm{O}_{4}$ nanowires synthesized by electroprecipitation in templates. J. Appl. Phys. 2005, 98, 086102. [CrossRef]

115. Kovalenko, M.V.; Bodnarchuk, M.I.; Lechner, R.T.; Hesser, G.; Schäffler, F.; Heiss, W. Fatty acid salts as stabilizers in size-and shape-controlled nanocrystal synthesis: The case of inverse spinel iron oxide. J. Am. Chem. Soc. 2007, 129, 6352-6353. [CrossRef]

116. Zhao, Z.; Zhou, Z.; Bao, J.; Wang, Z.; Hu, J.; Chi, X.; Ni, K.; Wang, R.; Chen, X.; Chen, Z.; et al. Fatty acid salts as stabilizers in size-and shape-controlled nanocrystal synthesis: The case of inverse spinel iron oxide. Nat. Commun. 2013, 4, 2266. [CrossRef]

117. Mohapatra, J.; Mitra, A.; Aslam, M.; Bahadur, D. Octahedral-shaped $\mathrm{Fe}_{3} \mathrm{O}_{4}$ nanoparticles with enhanced specific absorption rate and $R_{2}$ relaxivity. IEEE Trans. Magn. 2015, 51, 1-3. [CrossRef]

118. Nemati, Z.; Alonso, J.; Rodrigo, I.; Das, R.; Garaio, E.; García, J.Á.; Orue, I.; Phan, M.-H.; Srikanth, H.J. Improving the heating efficiency of iron oxide nanoparticles by tuning their shape and size. Phys. Chem. C 2018, 122, 2367-2381. [CrossRef]

119. Vestal, C.R.; Song, Q.; Zhang, Z.J.J. Effects of Interparticle Interactions upon the Magnetic Properties of $\mathrm{CoFe}_{2} \mathrm{O}_{4}$ and $\mathrm{MnFe}_{2} \mathrm{O}_{4}$ Nanocrystals. Phys. Chem. B 2004, 108, 18222-18227. [CrossRef]

120. Peddis, D.; Orrù, F.; Ardu, A.; Cannas, C.; Musinu, A.; Piccaluga, G. Interparticle interactions and magnetic anisotropy in cobalt ferrite nanoparticles: Influence of molecular coating. Chem. Mater. 2012, 24, 1062-1071. [CrossRef]

121. Gandhi, A.C.; Reddy, P.M.; Chan, T.S.; Ho, Y.P.; Wu, S.Y. Memory effect in weakly-interacting $\mathrm{Fe}_{3} \mathrm{O}_{4}$ nanoparticles. RSC Adv. 2015, 5, 84782-84789. [CrossRef]

122. Seehra, M.S.; Pisane, K.L.J. Relationship between blocking temperature and strength of interparticle interaction in magnetic nanoparticle systems. Phys. Chem. Solids 2016, 93, 79-81. [CrossRef] 
123. Aslibeiki, B.; Kameli, P.; Salamati, H.J. The effect of dipole-dipole interactions on coercivity, anisotropy constant, and blocking temperature of $\mathrm{MnFe}_{2} \mathrm{O}_{4}$ nanoparticles. Appl. Phys. 2016, 119, 063901. [CrossRef]

124. Balaev, D.A.; Semenov, S.V.; Dubrovskiy, A.A.; Yakushkin, S.S.; Kirillov, V.L.; Martyanov, O.N.J. Superparamagnetic blocking of an ensemble of magnetite nanoparticles upon interparticle interactions. J. Magn. Magn. Mater. 2017, 440, 199-202. [CrossRef]

125. Hiroi, K.; Komatsu, K.; Sato, T. Superparamagnetic blocking of an ensemble of magnetite nanoparticles upon interparticle interactions. Phys. Rev. B 2011, 83, 224423. [CrossRef]

126. Denisov, S.I.; Nefedchenko, V.F.; Trohidou, K.N.J. Dipolar ferromagnetism in ensembles of ellipsoidal nanoparticles. Phys. Condens. Matter 2000, 12, 7111-7115. [CrossRef]

127. Alkadour, B.; Mercer, J.I.; Whitehead, J.P.; Southern, B.W.; van Lierop, J. Dipolar ferromagnetism in three-dimensional superlattices of nanoparticles. Phys. Rev. B 2017, 95, 214407. [CrossRef]

128. Kostopoulou, A.; Brintakis, K.; Vasilakaki, M.; Trohidou, K.N.; Douvalis, A.P.; Lascialfari, A.; Manna, L.; Lappas, A. Assembly-mediated interplay of dipolar interactions and surface spin disorder in colloidal maghemite nanoclusters. Nanoscale 2014, 6, 3764-3776. [CrossRef]

129. Di Corato, R.; Espinosa, A.; Lartigue, L.; Tharaud, M.; Chat, S.; Pellegrino, T.; Ménager, C.; Gazeau, F.; Wilhelm, C. Magnetic hyperthermia efficiency in the cellular environment for different nanoparticle designs. Biomaterials 2014, 35, 6400-6411. [CrossRef]

130. Moise, S.; Byrne, J.M.; El Haj, A.J.; Telling, N.D. The potential of magnetic hyperthermia for triggering the differentiation of cancer cells. Nanoscale 2018, 10, 20519-20525. [CrossRef] [PubMed]

131. Calatayud, M.P.; Soler, E.; Torres, T.E.; Campos-Gonzalez, E.; Junquera, C.; Ibarra, M.R.; Goya, G.F. Cell damage produced by magnetic fluid hyperthermia on microglial BV2 cells. Sci. Rep. 2017, 7, 8627. [CrossRef] [PubMed]

132. Gupta, J.; Mohapatra, J.; Bhargava, P.; Bahadur, D. A pH-responsive folate conjugated magnetic nanoparticle for targeted chemo-thermal therapy and MRI diagnosis. Dalton Trans. 2016, 45, 2454-2461. [CrossRef] [PubMed]

133. Jaiswal, M.K.; Gogoi, M.; Dev Sarma, H.; Banerjee, R.; Bahadur, D. Biocompatibility, biodistribution and efficacy of magnetic nanohydrogels in inhibiting growth of tumors in experimental mice models. Biomater. Sci. 2014, 2, 370-380. [CrossRef]

134. Nandwana, V.; Zhou, R.; Mohapatra, J.; Kim, S.; Prasad, P.V.; Liu, J.P.; Dravid, V.P. Correlation between Structural Changes and Electrical Transport Properties of Spinel $\mathrm{ZnFe}_{2} \mathrm{O}_{4}$ Nanoparticles under High Pressure. ACS Appl. Mater. Interfaces 2018, 10, 27233-27243. [CrossRef]

135. Robles, J.; Das, R.; Glassell, M.; Phan, M.H.; Srikanth, H. Exchange-coupled $\mathrm{Fe}_{3} \mathrm{O}_{4} / \mathrm{CoFe}_{2} \mathrm{O}_{4}$ nanoparticles for advanced magnetic hyperthermia. AIP Adv. 2018, 8, 056719. [CrossRef]

136. Nemati, Z.; Alonso, J.; Khurshid, H.; Phan, M.H.; Srikanth, H. Exchange bias effects in iron oxide-based nanoparticle systems. RSC Adv. 2016, 6, 38697-38702. [CrossRef]

137. Lottini, E.; López-Ortega, A.; Bertoni, G.; Turner, S.; Meledina, M.; Van Tendeloo, G.; de Julián Fernández, C.; Sangregorio, C. Strongly exchange coupled core| shell nanoparticles with high magnetic anisotropy: A strategy toward rare-earth-free permanent magnets. Chem. Mater. 2016, 28, 4214-4222. [CrossRef]

138. Fabris, F.; Lima, E.; De Biasi, E.; Troiani, H.E.; Vásquez Mansilla, M.; Torres, T.E.; Fernández Pacheco, R.; Ibarra, M.R.; Goya, G.F.; Zysler, R.D.; et al. Controlling the dominant magnetic relaxation mechanisms for magnetic hyperthermia in bimagnetic core-shell nanoparticles. Nanoscale 2019, 11, 3164-3172. [CrossRef]

139. Song, Q.; Zhang, Z.J. Controlled synthesis and magnetic properties of bimagnetic spinel ferrite $\mathrm{CoFe}_{2} \mathrm{O}_{4}$ and $\mathrm{MnFe}_{2} \mathrm{O}_{4}$ nanocrystals with core-shell architecture. J. Am. Chem. Soc. 2012, 134, 10182-10190. [CrossRef]

140. He, S.; Zhang, H.; Liu, Y.; Sun, F.; Yu, X.; Li, X.; Zhang, L.; Wang, L.; Mao, K.; Wang, G.; et al. Maximizing specific loss power for magnetic hyperthermia by hard-soft mixed ferrites. Small 2018, 14, 1800135. [CrossRef] [PubMed]

(C) 2019 by the authors. Licensee MDPI, Basel, Switzerland. This article is an open access article distributed under the terms and conditions of the Creative Commons Attribution (CC BY) license (http://creativecommons.org/licenses/by/4.0/). 